\title{
Study on the influence of work-hardening modeling in springback prediction
}

\author{
M.C. Oliveira ${ }^{\mathrm{a}, *}$, J.L. Alves ${ }^{\mathrm{b}}$, B.M. Chaparro ${ }^{\text {c }}$, L.F. Menezes ${ }^{\mathrm{a}}$ \\ ${ }^{a}$ CEMUC, Department of Mechanical Engineering, University of Coimbra, Polo II, Rua Luís Reis Santos, \\ Pinhal de Marrocos, 3030-788 Coimbra, Portugal \\ ${ }^{\mathrm{b}}$ Department of Mechanical Engineering, University of Minho, Campus de Azurém, 4800-058 Guimarães, Portugal \\ c Polytechnic Institute of Tomar, Rua 17 de Agosto de 1808, 2200-273 Abrantes, Portugal
}

Received 29 January 2006

Available online 27 October 2006

\begin{abstract}
The main goal of this study is to evaluate the influence of work-hardening modeling in springback prediction in the first phase of the Numisheet'05 "Benchmark 3": the U-shape "Channel Draw". Several work-hardening constitutive models are used in order to allow the different materials' mechanical behavior to be better described: the Swift law (a power law) or a Voce type saturation law to describe the classical isotropic work-hardening; a Lemaitre and Chaboche type law to model the non-linear kinematic hardening, which can be combined with the previous two; and Teodosiu's microstructural work-hardening model. This analysis was carried out using two steels currently used in the automotive industry: mild (DC06) and dual phase (DP600). Haddadi et al. [Haddadi, H., Bouvier, S., Banu, M., Maier, C., Teodosiu, C., 2006. Towards an accurate description of the anisotropic behaviour of sheet metals under large plastic deformations: Modelling, numerical analysis and identification. Int. J. Plasticity 22 (12), 2226-2271] performed the mechanical characterization of these steels, as well as the identification of the constitutive parameters of each work-hardening model, based on an appropriate set of experimental data such as uniaxial tensile tests, monotonic and Bauschinger simple shear tests and orthogonal strain-path change tests, all at various orientations with respect to the rolling direction of the sheet. All the simulations were carried out with the inhouse FE code DD3IMP. The selected sheet metal formed component induces high levels of equivalent plastic strain. However, for the several work-hardening models tested, the differences in springback prediction are not significantly higher than those previously reported for components with lower equivalent plastic strain levels. It is shown that these differences can be related to the predicted
\end{abstract}

\footnotetext{
* Corresponding author. Tel.: +351 239 790700; fax: +351 239790701.

E-mail address: marta.oliveira@dem.uc.pt (M.C. Oliveira).
} 
through-thickness stress gradients. The comparative significance of both equivalent plastic strain levels and strain-path changes in the through-thickness stress gradients is discussed.

(c) 2006 Elsevier Ltd. All rights reserved.

Keywords: B. Constitutive behavior; B. Residual stress; B. Elastoplastic material; C. Finite elements

\section{Introduction}

Among other relevant specifications of the formed components, their near-net-shape characteristics are very important since they determine the success of the forming process. The near-net-shape is strongly compromised by the occurrence of defects such as excessive thinning, wrinkling, surface deflections and springback. Springback is one of the main sources of geometrical and dimensional inaccuracy in sheet metal formed components. A review of the relevant literature shows that researchers have been studying this phenomenon for the last four decades. The studies point out that the final shape of the part depends upon the amount of elastic energy stored in the part during the sheet metal forming process (Narasimhan and Lovell, 1999). Unfortunately, since the amount of elastic energy stored is a function of many parameters, springback prediction is a complicated task. The great sensitivity of springback prediction to the numerical parameters of finite element (FE) simulation also contributes to this complexity. Among other numerical parameters influencing springback, the authors point out the type, order and integration scheme of finite elements as well as the shape and size of the finite element mesh (Lee and Yang, 1998; Li et al., 2002a; Zhao and Lee, 2002; Oliveira et al., 2002), the time integration formulae (Lee and Yang, 1998; Lee et al., 1999; Narasimhan and Lovell, 1999) and the unloading strategy (Kawka et al., 1998; Li et al., 2002a). All these numerical parameters contribute to making the numerical simulation of springback more sensitive to numerical tolerances than the forming operation (Lee and Yang, 1998).

The springback FE prediction strongly depends on the accurate simulation and realistic modeling of the forming operation in order to correctly predict the final state variables, such as stress and strain states. The springback phenomenon is known to be influenced by tool design and lubrication (Carden et al., 2002; Geng and Wagoner, 2002; Li et al., 2002b; Yoshida and Uemori, 2003) as well as by material properties. The constitutive models used in the FEM simulation of industrial applications are usually based on phenomenological laws where material parameters are identified by means of a fit of the models to mechanical experimental test data.

To obtain accurate numerical solutions, mechanical models implemented in simulation algorithms should use reliable descriptions of the materials' elastoplastic behavior, namely a description of the anisotropy and the work-hardening behaviors. Thus, more sophisticated constitutive models, which take into account non-linear kinematic hardening and more complex internal state variables, as well as a better description of the yield locus, are expected to allow an improvement in the accuracy of the sheet metal forming simulations.

The most widely used constitutive model is the one based on the classical Hill'48 yield criterion to characterize the anisotropy and a power law to describe the isotropic workhardening, with the constitutive parameters being identified from experimental uniaxial 
tensile test results. However, during a stamping operation, neither the stress states nor the strain-paths correspond to the ones found during uniaxial tensile testing, even in a single stage process. In fact, FE springback prediction is strongly dependent on how the constitutive model describes the sheet metal's mechanical behavior under a strain-path change, such as the stress reversal occurring during the bending to unbending transition on the die radius or drawbeads (Alves et al., 2005). It should be pointed out that one of the reasons for the lack of accuracy in springback prediction is that strain-path changes occur during the forming process. The phenomenon that leads to a difference in the flow stress before unloading and after reloading in the reverse direction is known as the Bauschinger effect. However, if the second strain-path is orthogonal to the first an increase in flow stress can be observed, known as cross-hardening effect. Both Bauschinger and cross-hardening effects show that describing the evolution of the flow stress during the forming process simply using isotropic work-hardening modeled by a power law as a function of the equivalent plastic strain does not provide an accurate simulation of the sheet metal's mechanical behavior and thus of the real forming process.

The continuous improvements in polycrystalline metal plasticity based on texture analysis and texture evolution allow improved prediction of mechanical behavior under complex loading conditions (Peeters et al., 2001a,b,c, 2002; Li et al., 2003). However the use of micro-mechanical models in FE simulation of the forming process is still impractical due to the enormous computational cost and the amount of time required (Hiwatashi et al., 1997). A suitable way seems to be to enhance the phenomenological models in order to improve the description of yield surface evolution during the forming process. To describe the Bauschinger and cross-hardening effects, more sophisticated phenomenological models have been developed, like the one recently proposed by Choi et al. (2006a) or the former proposed by Teodosiu and $\mathrm{Hu}$ (1995). The Choi et al. (2006a) anisotropic hardening constitutive model describes the anisotropy evolution with the rotation of the yield function along with common isotropic and kinematic hardening. Teodosiu and Hu's (1995) anisotropic hardening constitutive model is a dislocation based microstructural model that considers the dislocation structure as the dominant cause of anisotropy under strain-path changes at moderately large strains. The yield surface expands and moves in the stress space: the isotropic expansion is dictated by the evolution of the intragranular structure; the displacement, which is associated with the kinematic hardening modeled by a generalized back-stress tensor, is physically based on the dislocations pile-ups (Hiwatashi et al., 1997). This model is able to capture both the Bauschinger and cross-hardening effects (Hiwatashi et al., 1997, 1998; Haddadi et al., 2006).

In brief, springback is influenced by material properties such as elastic behavior (Morestin and Boivin, 1996; Cleveland and Ghosh, 2002; Yang et al., 2004; Alves et al., 2006), the initial anisotropy resulting from sheet rolling conditions (Leu, 1997; Geng and Wagoner, 2002; Papeleux and Ponthot, 2002; Kyriakides et al., 2004; Alves et al., 2004b), work-hardening (Wang et al., 1993; Clausen et al., 2001; Papeleux and Ponthot, 2002) and, particularly, the Bauschinger effect (Gau and Kinzel, 2001; Li et al., 2002a; Geng et al., 2002; Yoshida and Uemori, 2003; Kyriakides et al., 2004; Lee et al., 2005; Choi et al., 2006b).

In recent years several advanced constitutive models have been implemented and tested for their ability to predict springback with several finite element codes. An example of this is DD3IMP, an in-house finite element research-purpose code that has been continuously developed and optimized since the end of the 80 s to simulate sheet metal forming processes 
(Menezes and Teodosiu, 2000; Oliveira et al., 2003a). With this code the shape of the yield locus can be described by several anisotropic yield criteria, namely: (i) Hill'48 (Hill, 1948); (ii) Barlat'91 (Barlat et al., 1991); (iii) Drucker +L (Cazacu and Barlat, 2001); (iv) Karafillis \& Boyce'93 (Karafillis and Boyce, 1993) and (v) Cazacu \& Barlat'01 (Cazacu and Barlat, 2001). The FE code also allows the use of different work-hardening laws to describe the evolution of the yield surface with plastic work, including: (i) pure isotropic hardening models by means of a power law (Swift) or a Voce type saturation law; (ii) the combination of these two laws with a non-linear kinematic hardening law (Lemaitre and Chaboche, 1985) or (iii) the microstructural hardening model proposed by Teodosiu and $\mathrm{Hu}$ (1995).

Several studies have focused on the influence of work-hardening models on springback prediction. Gau and Kinzel (2001) reported a maximum difference in springback angle predicted by isotropic hardening and kinematic hardening models of $4^{\circ}$, for a draw-bent test comprising two tension-compression cycles. Their study highlights the fact that strainpath changes affect the predicted differences between work-hardening models. This result was also confirmed by the analysis of the U-draw bending presented at the Numisheet'93 conference. The area that is only subjected to bending presents less variation due to springback than the region where bending and unbending occurs (Papeleux and Ponthot, 2002). Papeleux and Ponthot (2002) report a maximum difference in the springback angle numerically predicted by an isotropic hardening model and a kinematic hardening model of about $7^{\circ}$. Lee et al. (2005) confirmed these results for the U-shape rail, showing also an underestimation of the springback phenomenon associated with the exclusive use of a kinematic hardening model. However, exclusive use of the isotropic hardening model leads to an overestimation of the springback phenomenon. Taking into account the Bauschinger effect, the FE simulation of the draw-bent test leads to a $5-9^{\circ}$ reduction in the predicted springback angle when compared with only isotropic hardening simulation results (Geng and Wagoner, 2002). Additionally, the work of Geng and Wagoner (2002) demonstrates that the differences in the predicted springback angle using different work-hardening models are also dependent on the process conditions, particularly the ones that determine the in-plane sheet tension. For the same draw-bent test Li et al. (2002a) conclude that the inclusion of the Bauschinger effect in constitutive modeling reduces the deviation from the experimental results by about $50 \%$, when compared to the deviation obtained with only isotropic hardening. Nevertheless, it was also shown that for some particular process conditions, the differences in springback prediction using several work-hardening models can be smaller than the values previously mentioned (Yoshida and Uemori, 2003).

Several numerical studies regarding the influence of constitutive modeling on the numerical simulation of deep-drawing processes and springback prediction have been performed with DD3IMP FE code (Menezes et al., 2002; Chaparro et al., 2004; Bouvier et al., 2005). The main conclusions of these studies point out that the modeling of kinematic hardening is important when the blank sheet is submitted to strong strain-path changes, such as the typical bending/unbending due to die radius. The effects of these strain-path changes on springback cannot be accurately numerically predicted if only isotropic work-hardening is considered, even if the level of equivalent plastic strain is low, which is in agreement with other authors' conclusions (Geng and Wagoner, 2002; Li et al., 2002a; Yoshida and Uemori, 2003; Lee et al., 2005; Choi et al., 2006b). The small normalized differences in springback angle reported between Teodosiu's microstructural model and the constitutive models that take into account both isotropic and kinematic hardening 
were usually associated with the low levels of equivalent plastic strain $(<15 \%)$ occurring in the studied examples, and thus with the related small differences in the predicted throughthickness stress gradients.

The aim of this study is to investigate the influence of the different constitutive models on the numerical simulation of a sheet metal formed component submitted to several bending/unbending strain-path changes, during which a high level of equivalent plastic strain is attained. Firstly a brief description of the finite element code DD3IMP is presented. The constitutive models used are summarized and the state update algorithm briefly reviewed. The first phase of the Numisheet'05 "Benchmark 3", the U-shape "Channel Draw", is simulated. All simulations were carried out with a fixed set of numerical parameters in order to numerically evaluate the influence of all the above mentioned constitutive models on springback prediction.

\section{DD3IMP - the finite element code}

The finite element code DD3IMP (which stands for Deep-Drawing 3D Implicit code) has been specifically developed to simulate sheet metal forming processes. The evolution of the deformation process is described by an updated Lagrangian scheme. An explicit approach is used to calculate an approximate first solution for the nodal displacements, the stress states and frictional contact forces. A $r_{\text {min }}$ strategy is implemented to impose several restrictions on the size of the time increment in order to improve the convergence (Yamada et al., 1968). The first trial solution is iteratively corrected, using a NewtonRaphson algorithm, finishing when a satisfactory equilibrium state in the deformable body is achieved. It is then possible to update the blank sheet configuration, as well as all the state variables, passing on to the calculation of the next time increment. This is repeated until the end of the process (Menezes and Teodosiu, 2000).

\subsection{Boundary conditions}

In sheet metal forming processes the boundary conditions are dictated by the contact established between the blank sheet and the tools. Such boundary conditions continuously change during the forming process, increasing the importance of correctly evaluating the actual contact surface and the kind of contact that is established at each point of the deformable body. A master-slave algorithm is adopted, with the tools behaving as rigid bodies. Coulomb's classical law models the friction contact problem between the tools and the blank sheet (deformable body). The contact with friction problem is treated by an augmented Lagrangian approach (Oliveira et al., 2003a). Then the above mentioned fully implicit Newton-Raphson scheme is used to solve, in a single iterative loop, all the problem non-linearities associated with either the contact with friction problem or the elastoplastic behavior of the deformable body.

\subsection{Tool modeling and spatial discretization}

Forming tools are modeled by Bézier type parametric surfaces. In order to improve both the numerical behavior of the contact search algorithm and thus the convergence rate of the implicit scheme, continuity $C_{1}$, or at least $C_{0}$, must be guaranteed between the parametric surfaces (Oliveira et al., 2003a). The blank sheet is discretized with 3D solid finite elements. 
Although penalized in this type of applications by computational cost and effectiveness, solid elements have many advantages. Among others, they allow the accurate evaluation of the contact forces through an accurate description of contact evolution and thickness change; the simultaneous contact on both sides of the sheet is naturally solved without any particular strategy or tricky algorithms. Also, solid elements are required for accuracy in FE springback simulation when the ratio between the tool radius and blank thickness is lower than 5-6 ( Li et al., 2002a). These facts have motivated recent studies of the improvement of solid elements for sheet metal forming simulations (Jiao and Li, 2000; Areias et al., 2003; Wang and Wagoner, 2005; Reese, 2005). In this study a traditional tri-linear eightnode hexahedral finite element associated with a selective reduced integration scheme (SRI) is adopted (Hughes, 1980). Although the SRI scheme in torsion-dominant problems can exhibit spurious zero-energy modes, this kind of finite elements allows efficient computation of the thickness evolution (Menezes et al., 1991; Alves and Menezes, 2001) as well as the through-thickness stress gradients (Oliveira et al., 2002), depending on the type of applications and on the number of elements thought thickness and in sheet plane.

\subsection{Springback strategies}

With regard to springback simulation, DD3IMP allows the use of three different strategies to simulate the unloading phase. The first one can be understood as a simple continuation of the forming process, as the tools' motion is reversed and the computation is carried out until the end of the process (loss of contact between the tools and the formed part). This unloading strategy is in very close agreement with the physics of the real process itself, since it allows the changes in the contact areas between the blank sheet and tools during the unloading phase to be tracked. However, this procedure leads to a significant increase in CPU time due to the reversing tools' displacement and can lead to convergence problems due to the discrete character of the contact. The second possible strategy consists of removing the tools, one by one, using only one time increment per tool (punch, die...), forcing the equilibrium at each step by an implicit equilibrium iterative loop. The third strategy performs springback in only one step, removing all the tools simultaneously and forcing the blank sheet to attain equilibrium. In this last strategy, named "One Step Springback", all the constraints imposed by the tools vanish at the beginning of the unloading phase. There is no need to perform a trial solution since the initial solution for the implicit scheme corresponds to the configuration at the end of the forming phase. The "One Step Springback" strategy is implemented in DD3IMP through a module designated DD3OSS. These strategies were compared for a U-rail and a curved rail, confirming that for rail type geometries the differences between these strategies seem to be negligible in terms of the predicted geometries after springback. However, in terms of CPU time, the "One Step Springback" strategy is clearly the least expensive (Oliveira et al., 2003b). Li et al. (2002a) also tested different unloading strategies for the draw-bend test geometry and concluded that the choice of the unloading scheme has little effect on the result for this type of geometry.

\subsection{Equilibrium equation}

In the following, tensors are denoted by boldface characters and the superposed dot denotes the material time derivative. $\otimes$ denotes a tensor product. 
The mechanical model takes into account large elastoplastic strains and rotations and assumes that the elastic strains are negligibly small with respect to unity. Elastic behavior is assumed to be isotropic. The updated Lagrangian formulation implemented is based on the principle of virtual velocities proposed by McMeeking and Rice (1975), and given by

$$
\int_{\Omega}\left\{\left(\dot{\sigma}_{i j}^{\mathrm{J}}-2 \sigma_{i k} D_{k j}\right) \delta D_{i j}+\sigma_{j k} L_{i k} \delta L_{i j}\right\} \mathrm{d} \Omega=\int_{\Sigma} \dot{s}_{i}^{*} \delta v \mathrm{~d} \Sigma .
$$

This equation should be fulfilled for any virtual velocity field $\delta v$, at any instant of the deformation process. $\Omega$ is the domain of the deformable body submitted to external forces, which has a surface boundary $\Sigma$ at instant $t$. $\dot{\sigma}^{\mathrm{J}}$ is the rate of variation according to the Jaumann derivative of the Cauchy stress tensor $\boldsymbol{\sigma}$. $\mathbf{L}$ is the gradient of the velocity field and $\mathbf{D}$ is the strain rate tensor, which is the symmetric part of $\mathbf{L} . \mathbf{s}^{*}$ is the prescribed nominal stress vector expressing the external load. The principle of virtual velocities in this form involves the tensors that occur directly in the formulation of the constitutive models (Menezes and Teodosiu, 2000).

\subsection{Constitutive models}

The constitutive equation that models the materials' mechanical behavior establishes the relationship between the most relevant state variables characterizing the continuum medium. The differential form of the constitutive equation is given by

$$
\dot{\boldsymbol{\sigma}}^{\mathrm{J}}=\mathbf{C}^{\mathrm{ep}}: \mathbf{D}
$$

where $\mathbf{C}^{\mathrm{ep}}$ is a fourth-order tensor that defines the elastoplastic modulus according to the adopted constitutive model (work-hardening laws and yield criterion), depending on the algorithm used for the time integration scheme.

In the following it is assumed that constitutive modeling is formulated in the objective frame, and thus all tensorial quantities are invariant. To model plastic behavior it is necessary to define the flow rule, the yield surface and its evolution. Plasticity is associated, i.e., the following associated flow rule is adopted:

$$
\mathbf{D}^{\mathrm{p}}=\dot{\lambda} \frac{\partial \mathscr{F}(\bar{\sigma}, Y)}{\partial \boldsymbol{\sigma}},
$$

where $\mathbf{D}^{\mathrm{p}}$ is the plastic strain rate tensor, $Y$ is the flow stress in simple tension and $\bar{\sigma}$ is an equivalent tensile stress computed from the chosen yield criterion. $\dot{\lambda}$ is the plastic multiplier that can be demonstrated to be equal to the equivalent plastic strain rate, $\dot{\bar{\varepsilon}}^{\mathrm{p}}$.

The equivalent plastic strain, $\bar{\varepsilon}^{\mathrm{p}}$, can be computed from

$$
\bar{\varepsilon}^{\mathrm{p}}=\int_{0}^{t} \dot{\bar{\varepsilon}}^{\mathrm{p}} \mathrm{d} t=\int_{0}^{t} \frac{\boldsymbol{\Sigma}: \mathbf{D}^{\mathrm{p}}}{\bar{\sigma}} \mathrm{d} t,
$$

where $\boldsymbol{\Sigma}=\boldsymbol{\sigma}^{\prime}-\mathbf{X}$ is the effective deviatoric stress tensor. $\boldsymbol{\sigma}^{\prime}$ is the Cauchy's deviatoric stress tensor and $\mathbf{X}$ is the back-stress tensor. The evolution law of $\mathbf{X}$ depends on the adopted kinematic hardening law.

The yield condition can be formulated in a generic form as

$$
\mathscr{F}(\bar{\sigma}, Y)=\bar{\sigma}-Y=0 .
$$


In this study the anisotropic model used to compute the equivalent stress $\bar{\sigma}$ is the classical Hill'48 yield criterion, given by

$$
\bar{\sigma}^{2}=\left(\boldsymbol{\sigma}^{\prime}-\mathbf{X}\right): \mathbf{M}:\left(\boldsymbol{\sigma}^{\prime}-\mathbf{X}\right),
$$

where $\mathbf{M}$ is a fourth-order symmetric tensor, which is function of the anisotropy parameters of the Hill'48 yield criterion: $F, G, H, L, M$ and $N$.

The global and objective frames are related throughout the rotation tensor $\mathbf{R}$, which is derived from the polar decomposition of the deformation gradient $\mathbf{F}$. The evolution of the rotation tensor $\mathbf{R}$ during the process is governed by the differential equation

$$
\dot{\mathbf{R}}=\left(\mathbf{W}-\mathbf{W}^{\mathrm{p}}\right) \mathbf{R} \approx \mathbf{W R}, \quad \text { with } \mathbf{R}(0)=\mathbf{0},
$$

where $\mathbf{W}$ is the total spin tensor, that is the anti-symmetric part of $\mathbf{L}$, and $\mathbf{W}^{\mathrm{p}}$ is the plastic spin tensor assumed to be negligibly small (Teodosiu, 1989).

The isotropic work-hardening law describes the evolution of the flow stress with plastic work. In a generic form, this law can be formulated as

$$
Y=f\left(\bar{\varepsilon}^{\mathrm{p}}\right) \text {. }
$$

The laws most commonly used to describe the isotropic component of the work-hardening are the Swift law, given by

$$
Y=C\left(\varepsilon_{0}+\bar{\varepsilon}^{\mathrm{p}}\right)^{n},
$$

and, for materials that show some saturation of flow stress, the Voce type equation law, given by the following equations:

$$
Y=Y_{0}+R, \quad \text { with } \dot{R}=C_{\mathrm{R}}\left(R_{\mathrm{sat}}-R\right)^{\dot{\bar{\varepsilon}}^{\mathrm{p}}} \quad \text { and } R(0)=0,
$$

$C, \varepsilon_{0}, n$, and $Y_{0}, R_{\text {sat }}, C_{\mathrm{R}}$ are the material parameters for the Swift and Voce laws, respectively.

The kinematic part of the work-hardening, i.e. the evolution of the back-stress tensor $\mathbf{X}$, can be described by a non-linear law with saturation, modeled by the following equation:

$$
\dot{\mathbf{X}}=C_{\mathrm{X}}\left[\frac{X_{\text {sat }}}{\bar{\sigma}}\left(\boldsymbol{\sigma}^{\prime}-\mathbf{X}\right)-\mathbf{X}\right] \dot{\bar{\varepsilon}}^{\mathrm{p}}, \quad \text { with } \mathbf{X}(0)=\mathbf{0},
$$

where $C_{\mathrm{X}}$ and $X_{\text {sat }}$ are material parameters (Lemaître and Chaboche, 1985).

Teodosiu's work-hardening model is a dislocation based microstructural model that is able to describe the work-hardening stagnation that occurs after an orthogonal or inverse strain-path change (Teodosiu and Hu, 1995, 1998). It was developed in the general framework of cold deformation of metals, neglecting any viscous effects on work-hardening. Recently it was generalized to include rate and thermal effects (Uenishi and Teodosiu, 2004). The new internal state variables introduced by the model to describe the strain-path dependence of the material behavior are $\mathbf{S}, \mathbf{P}, \mathbf{X}$ and $R$. The fourth-order tensor $\mathbf{S}$ describes the directional strength of the intragranular dislocation structures, and has dimensions of stress; $\mathbf{P}$ is a dimensionless second-order tensor that is associated with the polarity of the planar persistent dislocation structures; the second-order tensor $\mathbf{X}$ is a generalized back-stress tensor, intended to describe the rapid changes in the flow stress following a sharp strain-path change; and $R$ is a scalar that describes the contributions of the randomly distributed dislocations to the isotropic hardening. The evolution equations of these four internal state variables bring out an improved modeling of the effects of the 
internal structure of dislocations on the material's mechanical behavior. Flow stress is given by

$$
Y=Y_{0}+R+f\|\mathbf{S}\|,
$$

where $Y_{0}$ is the initial yield stress and $f$ is a material parameter describing the material sensitivity to the microstructural evolution. The last term, $f\|\mathbf{S}\|$, is the contribution of the strength of the intragranular dislocation structures to the isotropic work-hardening. The evolution of internal state variables $R$ and $\mathbf{X}$ are described by Voce type equations (see Eqs. (10) and (11), respectively). However, the saturation value $X_{\text {sat }}$ is no longer a constant, but a function of the internal state variable $\mathbf{S}$

$$
X_{\mathrm{sat}}=X_{0}+(1-f) \sqrt{r\|\mathbf{S}\|^{2}+(1-r) S_{\mathrm{D}}^{2}},
$$

where $r$ and $X_{0}$ are material parameters. $S_{\mathrm{D}}=\mathbf{N}: \mathbf{S}: \mathbf{N}$ is the strength of the dislocation structures associated with the currently active slip systems. The tensor $\mathbf{N}=\mathbf{D}^{\mathrm{p}} /\left\|\mathbf{D}^{\mathrm{p}}\right\|$ is the direction of the plastic strain rate tensor, which is also used in the evolution equation of the internal state variable $\mathbf{P}$

$$
\dot{\mathbf{P}}=C_{\mathrm{p}}(\mathbf{N}-\mathbf{P}) \dot{\bar{\varepsilon}}^{\mathrm{p}},
$$

where $C_{\mathrm{p}}$ is a material parameter. The evolution of the internal variable $\mathbf{S}$ depends on the evolution laws of $S_{\mathrm{D}}$, previously defined, and $\mathbf{S}_{\mathrm{L}}$, which describes the strength of the latent part of the persistent dislocation structures, defined as

$$
\mathbf{S}_{\mathrm{L}}=\mathbf{S}-S_{\mathrm{D}} \mathbf{N} \otimes \mathbf{N} .
$$

The evolution laws of $S_{\mathrm{D}}$ and $\mathbf{S}_{\mathrm{L}}$ are given by

$$
\begin{aligned}
& \dot{S}_{\mathrm{D}}=C_{\mathrm{SD}}\left[g\left(S_{\mathrm{sat}}-S_{\mathrm{D}}\right)-h S_{\mathrm{D}}\right] \dot{\bar{\varepsilon}}^{\mathrm{p}} \\
& \dot{\mathbf{S}}_{\mathrm{L}}=-C_{\mathrm{SL}}\left(\frac{\left\|\mathbf{S}_{\mathrm{L}}\right\|}{S_{\text {sat }}}\right)^{n_{\mathrm{L}}} \mathbf{S}_{\mathrm{L}} \dot{\overline{\bar{\varepsilon}}}^{\mathrm{p}}
\end{aligned}
$$

where $C_{\mathrm{SD}}$ and $C_{\mathrm{SL}}$ characterize the saturation rate of $S_{\mathrm{D}}$ and $\mathrm{S}_{\mathrm{L}}$, respectively. $n_{\mathrm{L}}$ is a material parameter, $S_{\text {sat }}$ denotes the saturation value of $S_{\mathrm{D}}$, and $g$ and $h$ are scalar functions defined as

$$
\begin{aligned}
& g= \begin{cases}1-\frac{C_{\mathrm{p}}}{C_{\mathrm{p}}+C_{\mathrm{SD}}}\left|\frac{S_{\mathrm{D}}}{S_{\mathrm{sat}}}-P_{\mathrm{D}}\right| & \text { if } P_{\mathrm{D}} \geqslant 0, \\
\left(1+P_{\mathrm{D}}\right)^{n_{\mathrm{p}}}\left[1-\frac{C_{\mathrm{p}}}{C_{\mathrm{p}}+C_{\mathrm{SD}}} \frac{S_{\mathrm{D}}}{S_{\mathrm{sat}}}\right] & \text { if } P_{\mathrm{D}}<0,\end{cases} \\
& h=\frac{1}{2}\left[1-\frac{\mathbf{X}: \mathbf{N}}{X_{\mathrm{sat}}\left(\boldsymbol{\sigma}^{\prime}-\mathbf{X}\right): \mathbf{N}} \bar{\sigma}\right],
\end{aligned}
$$

where $P_{\mathrm{D}}=\mathbf{P}: \mathbf{N}$, and $n_{\mathrm{p}}$ is a material parameter. Teodosiu's microstructural model has 13 constitutive parameters: $Y_{0}, f, C_{\mathrm{R}}, R_{\mathrm{sat}}, C_{\mathrm{X}}, X_{0}, C_{\mathrm{p}}, C_{\mathrm{SD}}, C_{\mathrm{SL}}, S_{\mathrm{sat}}, n_{\mathrm{p}}, r$ and $n_{\mathrm{L}}$.

Once the constitutive model (work-hardening law and yield criterion) for a FE simulation is defined, it is possible to establish the relationships between the main state variables characterizing the continuum medium (see Eq. (2)). This involves the determination of the elastoplastic modulus, $\mathbf{C}^{\mathrm{ep}}$, according to the algorithm used for the time integration scheme. The tangent and consistent elastoplastic moduli are defined as the relationships between the Cauchy stress rate tensor and the strain rate tensor, in a total or incremental 
Table 1

State update algorithm

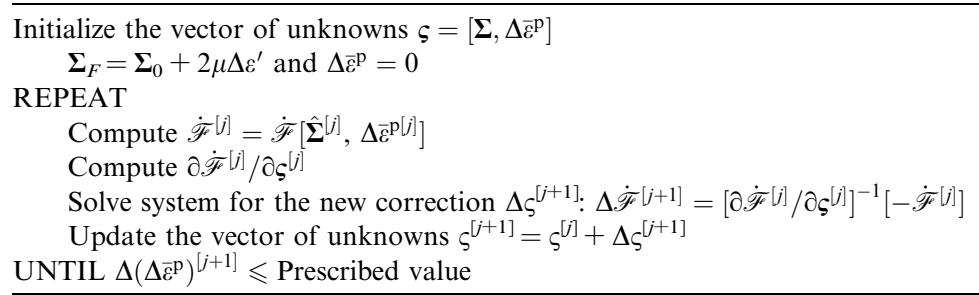

form, respectively. Their definition is of paramount importance for the state update algorithm. Both moduli can be deduced based on generic expressions of the constitutive model, the isotropic and/or kinematic work-hardening laws and the yield criterion. The tangent elastoplastic modulus, defined in the objective frame, is given by

$$
\mathbf{C}_{\mathrm{tan}}^{\mathrm{ep}}=\mathbf{C}^{\mathrm{e}}-\alpha f_{0} \mathbf{V} \otimes \mathbf{V},
$$

and the consistent elastoplastic modulus by

$$
\mathbf{C}_{\mathrm{con}}^{\mathrm{ep}}=\mathbf{C}_{\mathrm{e}}-4 \mu^{2}(1-\beta)\left(\frac{\mathbf{V} \otimes \mathbf{V}}{H^{\prime}}+\Delta \bar{\varepsilon}^{\overline{\mathrm{p}}} \mathbf{Q}\right) \mathbf{\Lambda},
$$

where $\mathbf{C}^{\mathrm{e}}$ is the elastic modulus and $H^{\prime}=\partial Y / \partial \bar{\varepsilon}^{\mathrm{p}}$ is the hardening modulus. $\mathbf{V}$ and $\mathbf{Q}$ are the first and second derivatives of the equivalent tensile stress in order to the effective deviatoric stress state

$$
\mathbf{V}=\partial \bar{\sigma} / \partial \boldsymbol{\Sigma} \text { and } \mathbf{Q}=\partial^{2} \bar{\sigma} / \partial \boldsymbol{\Sigma}^{2} .
$$

$\mu$ is the shear modulus, and $\alpha$ and $\beta$ are parameters that quantify the plastic and elastic part of the total elastoplastic increment, respectively. The scalar $f_{0}$ and the tensor $\boldsymbol{\Lambda}$ are functions of $H^{\prime}, \mathbf{V}$ and $\mathbf{Q}$, which assume different expressions according to the constitutive model chosen to describe the material behavior (Alves et al., 2004a).

The integration of the constitutive equation allows the incremental stress tensor and thus the final stress state to be determined, as well as the incremental equivalent plastic strain $\left(\Delta \bar{\varepsilon}^{p}\right)$ and the updated quantities of the internal variables at a given integration point. To determine these quantities the consistency condition, $\dot{\mathscr{F}}(\bar{\sigma}, Y)=0$, is imposed on the configuration at the end of the time increment. Since the problem is strongly non-linear, a Newton-Raphson algorithm is used. A brief description of the state update algorithm is presented in Table 1 (Alves et al., 2004a; Bouvier et al., 2005).

Mixing the above mentioned different strategies with the in-code implemented constitutive models, makes the 18-years-old DD3IMP FE code a unique freeware open-source labcode, with proven reliability in the testing of new solutions in the field of computational mechanics applied to sheet metal forming.

\section{Application}

\subsection{FE simulations of the U-shape "Channel Draw"}

The first phase of "Benchmark 3" of the Numisheet' 05 conference was selected to evaluate the influence of work-hardening modeling on the numerical prediction of springback. 
A scheme of the stamping tool geometry is presented in Fig. 1, as well as a detail of the drawbead geometry (Stoughton et al., 2005). The tool consists of a blank holder, a die and a punch. The kiss blocks shown in the figure are used to guarantee a fixed clearance between the die and the blank holder throughout the forming process. The drawbead controls the blank sheet inflow. The material which passes through the drawbead is included in the vertical wall of the final formed part. This example was selected because of the high levels of equivalent plastic strain attained in the final formed part, as a result of the material's flowing history along the drawbead and die radius (Alves et al., 2005). The different materials proposed in the frame of the Numisheet'05 "Benchmark 3" were experimentally characterized using only the uniaxial tensile test (Shi and Huang, 2005), which allows no more than the characterization of the isotropic work-hardening laws. The numerical results obtained with DD3IMP, for all the proposed materials, show a strong correlation with the published experimental results (Buranathiti and Cao, 2005; Oliveira et al., 2006). Despite the simplicity of the constitutive modeling used in the simulations, the comparison between experimental and numerical results seems to validate quite well the numerical model developed to simulate the proposed benchmark. However, bearing in mind that the aim of this study is to evaluate the influence of work-hardening modeling on springback prediction of the first phase of the Numisheet'05 "Benchmark 3", and the limitations of the lack of experimental results on the experimental characterization of the proposed materials, two other very well characterized steels were selected. These two steels, a mild (DC06) and a dual phase (DP600) steels, are briefly described in the next section.

The blank sheet is rectangular in shape, measuring $254.0 \mathrm{~mm}$ in the $O y$ direction by $1066.8 \mathrm{~mm}$ in the $O x$ direction and thickness of $1.0 \mathrm{~mm}$. The rolling direction corresponds to the $O y$ direction represented in Fig. 1. Due to geometrical and material symmetries only one quarter of the global structure was simulated. The numerical model takes into account the physical drawbead as represented in Fig. 1, in order to accurately reproduce its effect on the stamping process (Alves et al., 2005). The drawbead imposes on the blank sheet, which moves through, a series of restraining and bending forces associated with a sequence of bending, unbending and reverse bending. This cyclic bending introduces strains and stresses, plasticity and a thickness change (Nine, 1978; Meinders et al., 1998; Samuel, 2002; Courvoisier et al., 2003). The modeling of real drawbead geometry requires a refined
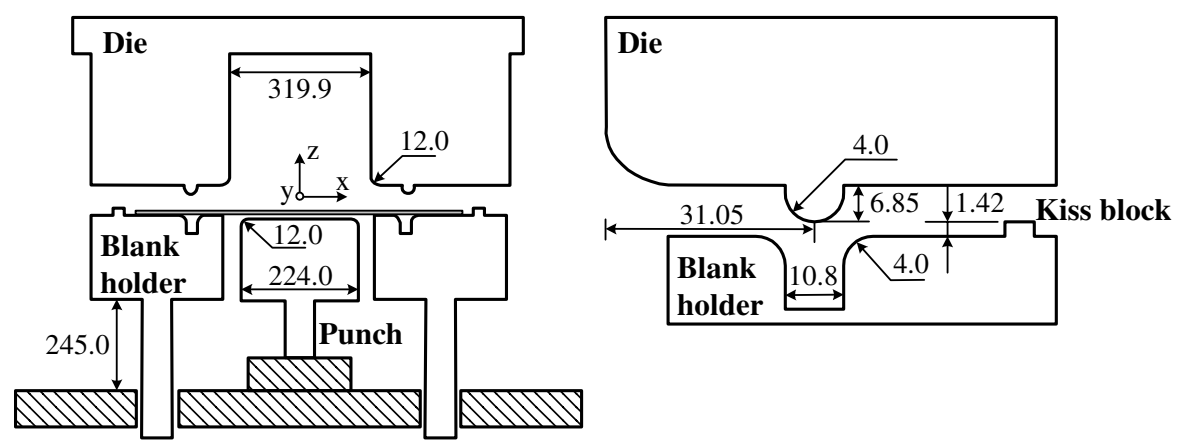

Fig. 1. Schematic representation of the stamping tool used for the first phase of the Numisheet'05 "Benchmark 3": the U-shape "Channel Draw". Detail of the drawbead geometry, drawbead channel and kiss blocks (units in $\mathrm{mm}$ ) (Stoughton et al., 2005). 
mesh due to its small radius (in this case $4.0 \mathrm{~mm}$ ). As the main goal of this study is to evaluate springback, three layers of 8-node solid elements were used through thickness. A regular mesh in the $O x z$ plane with a finite element ratio of 1.0 was used, which corresponds to a turning angle per element in contact with the tools of $4.8^{\circ}$ allowing an accurate prediction of springback (Li et al., 2002a; Oliveira et al., 2002). The numerical model for the U-shape channel consists of 25 Bézier parametric surfaces describing the tool geometry and $48003-\mathrm{D}$ solid finite elements discretizing the blank sheet. A selective reduced integration technique is used to integrate the solid tri-linear finite elements in order to avoid locking effects (Menezes and Teodosiu, 2000; Alves and Menezes, 2001). Since no comparison with experimental results will be carried out, a constant Coulomb's friction coefficient of 0.1 was selected. The effect of friction on springback occurs mainly by increasing the sheet tension ( $\mathrm{Li}$ et al., 2002a). Seeing that the restraining force is, in this study, basically dominated by the drawbead, the friction coefficient presents no effect on the comparative study of the different work-hardening laws. The unloading phase of the forming process is simulated with the aforementioned "One Step Springback" strategy.

\subsection{Materials}

This study looked at two well-characterized and commonly used steels in the automotive industry: mild (DC06) and dual phase (DP600) steels. The mechanical characterization and the constitutive parameters identification for each work-hardening model were performed by Bouvier et al. (2001). It is worth noting that, except for Teodosiu's microstructural model, the material parameters used in the actual simulations have been identified by the best fit to the experimental values, with all mechanical tests weighted equally. In case of Teodosiu's model, since some of its parameters describe specific parts of the stress-strain curves, the weights given to such parts were in general different (Haddadi et al., 2006). The identification of the constitutive parameters involved: (i) uniaxial tensile tests at various orientations with respect to the rolling direction up to localized necking, (ii) monotonic simple shear tests at various orientations with respect to the rolling direction up to $50 \%$ amount of shear, (iii) Bauschinger simple shear tests at various orientations with respect to the rolling direction, after 10\%, 20\% and 30\% amount of monotonic shear, and (iv) orthogonal strain-path change tests, accomplished by first imposing a true tensile strain of $10 \%$ and $20 \%$ in the rolling direction, and then simple shear in the same direction (Bouvier et al., 2001).

The mechanical behavior of both steels is assumed to be elastoplastic. The elastic behavior is isotropic and constant, with $E=210 \mathrm{GPa}$ and $v=0.30$; the anisotropic behavior is described by the Hill'48 yield criterion, with the anisotropy parameters also identified by Bouvier et al. (2001). Although other yield criteria are presently implemented and available in the DD3IMP FE code, the Hill'48 yield criterion was selected due to the range of experimental results available. In sheet metal forming, due to the complexity of the newly used materials, constitutive models based on non-quadratic yield criteria and/or more sophisticated yield functions are more accurate than the classical quadratic yield functions (Hiwatashi et al., 1998; Alves et al., 2004b; Stoughton and Yoon, 2006). This was not taken into account given that only the influence of work-hardening modeling was being investigated. Tables 2 and 3 show the complete set of constitutive parameters used in the numerical simulations, for both DC06 steel and DP600 steel, respectively. The label 
Table 2

Constitutive parameters of DC06 steel (Bouvier et al., 2001)

\begin{tabular}{|c|c|c|c|c|}
\hline Swift law & Swift law $+\mathrm{KH}$ & Voce law & Voce law $+\mathrm{KH}$ & Teodosiu law \\
\hline$Y_{0}=123.6 \mathrm{MPa}$ & $Y_{0}=122.2 \mathrm{MPa}$ & $Y_{0}=123.6 \mathrm{MPa}$ & $Y_{0}=122.24 \mathrm{MPa}$ & $Y_{0}=122.2 \mathrm{MPa}$ \\
\hline$C=529.5 \mathrm{MPa}$ & $C=435.0 \mathrm{MPa}$ & $C_{\mathrm{R}}=10.8$ & $C_{\mathrm{R}}=7.8$ & $C_{\mathrm{R}}=27.3$ \\
\hline \multirow[t]{5}{*}{$n=0.2680$} & $n=0.2190$ & $R_{\mathrm{sat}}=247.3 \mathrm{MPa}$ & $R_{\mathrm{sat}}=213.6 \mathrm{MPa}$ & $R_{\mathrm{sat}}=80.0 \mathrm{MPa}$ \\
\hline & $C_{\mathrm{X}}=1.45$ & & $C_{\mathrm{X}}=153.4$ & $C_{\mathrm{X}}=614.6$ \\
\hline & $X_{\mathrm{sat}}=116.7 \mathrm{MPa}$ & & $X_{\text {sat }}=45.1 \mathrm{MPa}$ & $X_{0}=6.9 \mathrm{MPa}$ \\
\hline & & & & $C_{\mathrm{SD}}=3.9$ \\
\hline & & & & $C_{\mathrm{SL}}=1.1$ \\
\hline Hill'48 parameters & & & & $S_{\text {sat }}=246.7$ \\
\hline$F=0.26350$ & & & & $n_{\mathrm{L}}=0.0$ \\
\hline$G=0.28329$ & & & & $n_{\mathrm{p}}=27.7$ \\
\hline$H=0.71671$ & & Elastic properties & & $r=1.9$ \\
\hline$L=M=1.50$ & & $E=210 \mathrm{GPa}$ & & $f=0.415$ \\
\hline$N=1.2947$ & & $v=0.30$ & & $C_{\mathrm{p}}=2.2$ \\
\hline
\end{tabular}

Table 3

Constitutive parameters of DP600 steel (Bouvier et al., 2001)

\begin{tabular}{|c|c|c|c|c|}
\hline Swift law & Swift law $+\mathrm{KH}$ & Voce law & Voce law $+\mathrm{KH}$ & Teodosiu law \\
\hline$Y_{0}=330.3 \mathrm{MPa}$ & $Y_{0}=308.3 \mathrm{MPa}$ & $Y_{0}=330.3 \mathrm{MPa}$ & $Y_{0}=308.3 \mathrm{MPa}$ & $Y_{0}=308.3 \mathrm{MPa}$ \\
\hline$C=1093.0 \mathrm{MPa}$ & $C=790.2 \mathrm{MPa}$ & $C_{\mathrm{R}}=16.3$ & $C_{\mathrm{R}}=6.75$ & $C_{\mathrm{R}}=49.7$ \\
\hline \multirow[t]{5}{*}{$n=0.1870$} & $n=0.1320$ & $R_{\mathrm{sat}}=516.4 \mathrm{MPa}$ & $R_{\mathrm{sat}}=365.6 \mathrm{MPa}$ & $R_{\mathrm{sat}}=125.2 \mathrm{MPa}$ \\
\hline & $C_{\mathrm{X}}=15.8$ & & $C_{\mathrm{X}}=73.7$ & $C_{\mathrm{X}}=53.5$ \\
\hline & $X_{\text {sat }}=169.2 \mathrm{MPa}$ & & $X_{\text {sat }}=225.3 \mathrm{MPa}$ & $X_{0}=153.0 \mathrm{MPa}$ \\
\hline & & & & $C_{\mathrm{SD}}=4.0$ \\
\hline & & & & $C_{\mathrm{SL}}=0.0$ \\
\hline Hill'48 parameters & & & & $S_{\mathrm{sat}}=387.2$ \\
\hline$F=0.51274$ & & & & $n_{\mathrm{L}}=0.0$ \\
\hline$G=0.49751$ & & & & $n_{\mathrm{p}}=649.0$ \\
\hline$H=0.50249$ & & Elastic properties & & $r=0.0$ \\
\hline$L=M=1.50$ & & $E=210 \mathrm{GPa}$ & & $f=0.862$ \\
\hline$N=1.27292$ & & $v=0.30$ & & $C_{\mathrm{p}}=0.13$ \\
\hline
\end{tabular}

" $+\mathrm{KH}$ " is added if the kinematic hardening is also taken into account in the constitutive modeling, in addition to the isotropic work-hardening (Swift or Voce labels).

The experimental results of the uniaxial tensile test, monotonic simple shear test, Bauschinger and orthogonal strain-path change tests are compared with analogous numerical results obtained with DD3IMP, in order to emphasize the differences between the constitutive models under study. Fig. 2 presents the results for DC06 steel obtained with isotropic work-hardening (Swift and Voce) combined with kinematic hardening $("+\mathrm{KH}$ ") and Teodosiu's model. Similar results are shown in Fig. 3, but for the DP600 steel.

Both steels exhibit work-hardening stagnation followed by resumption after a reversed strain-path change in Bauschinger tests. For DC06 steel a cross-hardening effect can also be seen after an orthogonal strain-path change, consisting of a rapid increase in the flow stress followed by softening. The DP600 steel presents no cross-hardening effect, which justifies the zero value of parameter $C_{\mathrm{SL}}$ that characterizes the saturation rate of $\mathbf{S}_{\mathrm{L}}$ (the strength of the latent part of the persistent dislocation structures). For DP600 steel the 

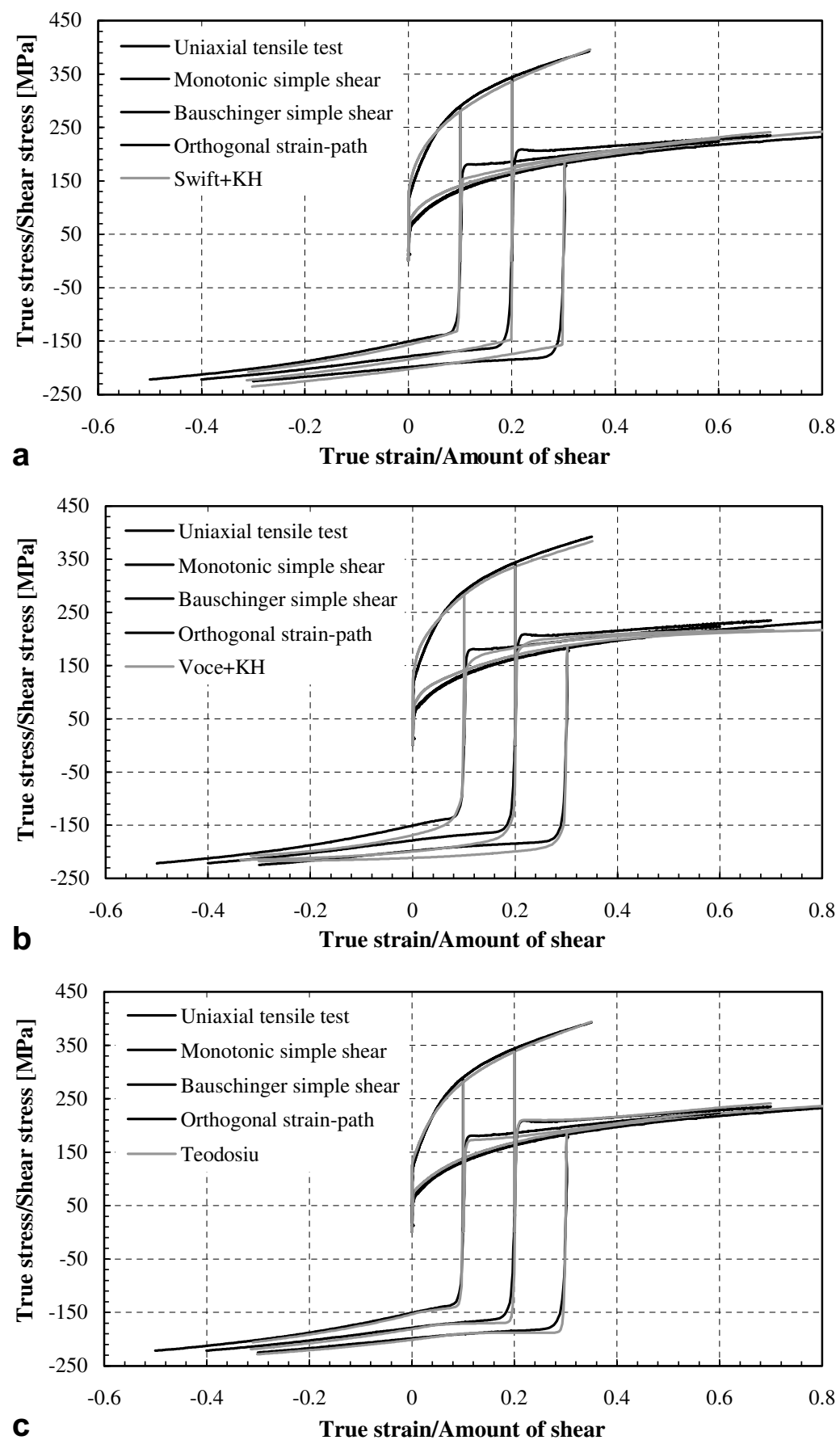

Fig. 2. Comparison between experimental (Haddadi et al., 2006) and numerical results for a uniaxial tensile test, monotonic and Bauschinger simple shear tests and an orthogonal strain-path change test for the DC06 steel with: (a) Swift law combined with kinematic hardening; (b) Voce law combined with kinematic hardening and (c) Teodosiu's model. 

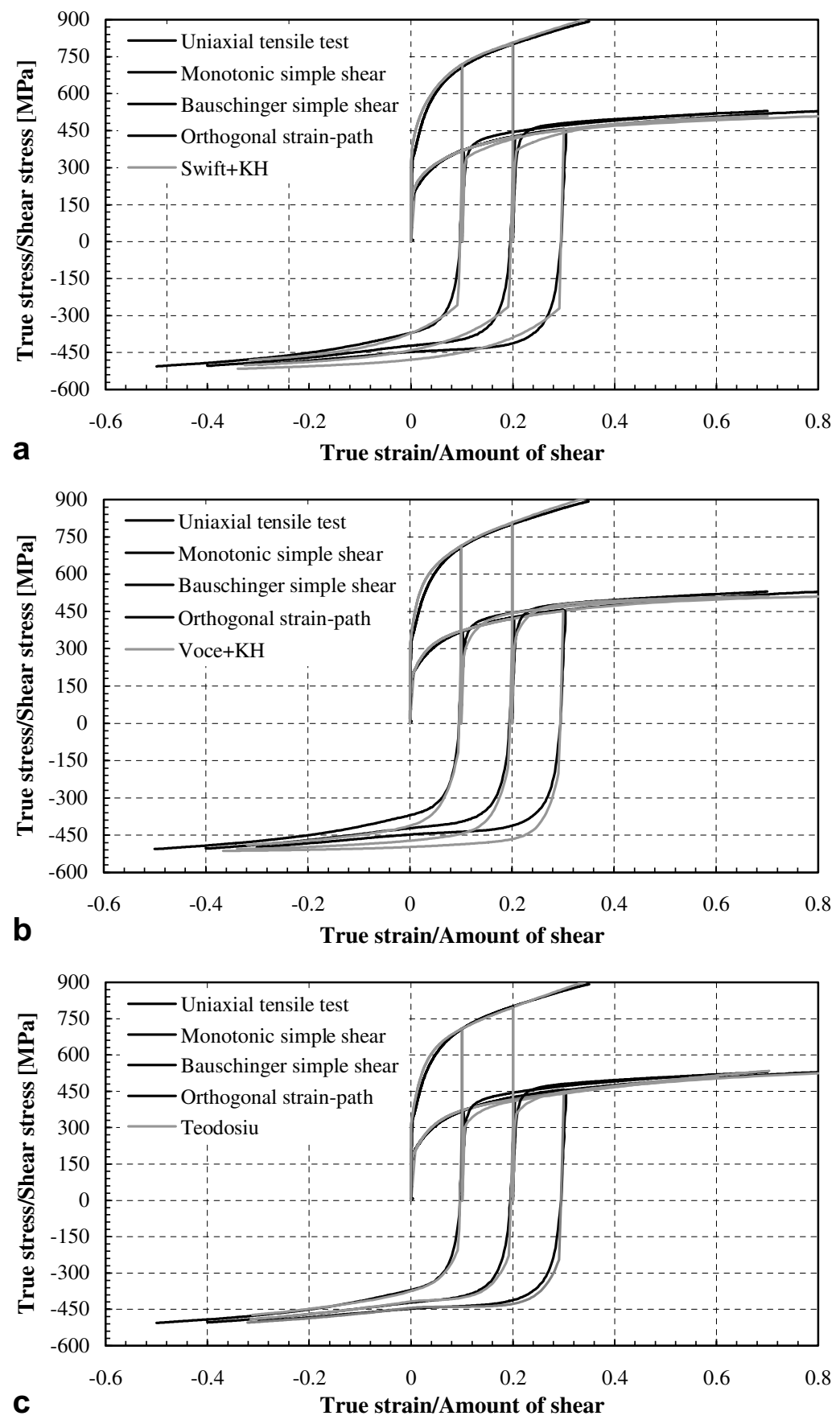

Fig. 3. Comparison between experimental (Haddadi et al., 2006) and numerical results for a uniaxial tensile test, monotonic and Bauschinger simple shear tests and an orthogonal strain-path change test for the DP600 steel with: (a) Swift law combined with kinematic hardening; (b) Voce law combined with kinematic hardening and (c) Teodosiu's model. 


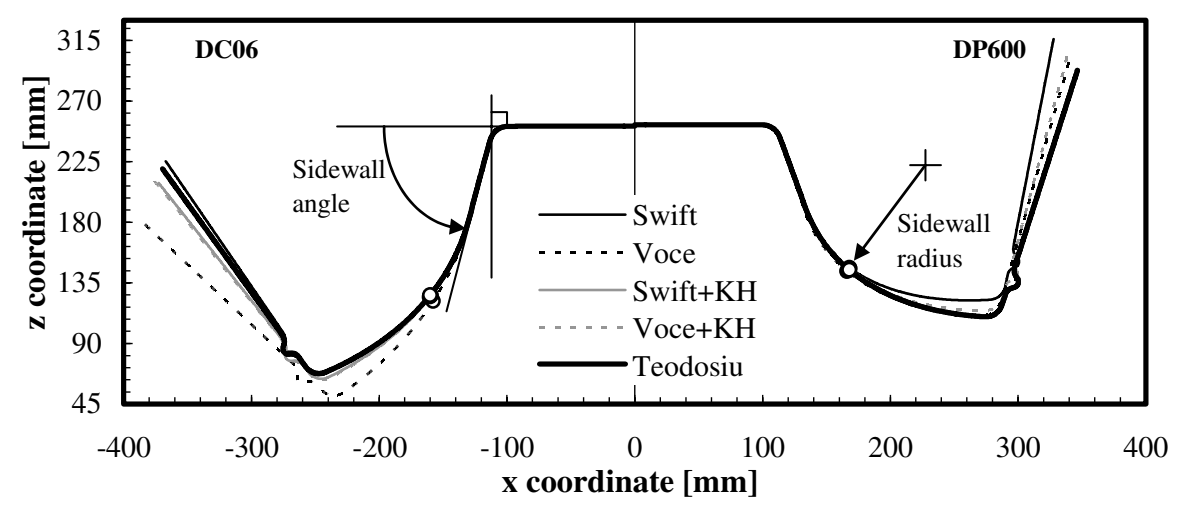

Fig. 4. Final shapes of the middle symmetry section as predicted by each constitutive model for the DC06 and DP600 steels.

material parameter $r$ is also zero, which indicates that the source of back-stress is the currently active structure of dislocations described by $\mathbf{S}_{\mathrm{D}}$. Both materials reveal a strong Bauschinger effect. The DC06 steel, during monotonic loading, exhibits a weak planar anisotropy of the flow stress. The DP600 is nearly isotropic regarding the flow stress.

Since none material displays saturation of the flow stress, their behaviors can be satisfactorily described by the Swift law combined with kinematic hardening, as can be confirmed from Fig. 2 for DC06 steel and Fig. 3 for the DP600 steel. However, only Teodosiu's model is able to accurately describe both work-hardening stagnation and the cross-hardening effect, as highlighted in Figs. 2 and 3 for the DC06 and DP600 steels, respectively (Haddadi et al., 2006). With regard to the Bauschinger effect, the analysis of these two figures allows the general increase in differences between experimental and numerical results as the prestrain level increases to be confirmed. Besides, although for low values of prestrain both the Swift law combined with kinematic hardening and Teodosiu's model seem to similarly describe the flow stress after a reversed load, for larger values of prestrain only Teodosiu's model seems to be able to accurately describe the flow stress after a Bauschinger test. Such behavior can justify the small differences in springback prediction reported in previous studies, for which the final levels of equivalent plastic strain were small (Chaparro et al., 2004; Bouvier et al., 2005).

\subsection{Results and discussion}

\subsubsection{Springback analysis}

The final part geometries obtained for each work-hardening model were evaluated using the "NXT Post Processor II"1 ${ }^{1}$ software package. Fig. 4 shows the middle symmetry section obtained for both materials and all constitutive models, after springback. Globally, it can be seen that after springback the geometries of all the sections are very close in the vicinity of the punch top, punch radius and at the top of the vertical wall. Fig. 5 presents the evolution of the turning angle throughout the above mentioned symmetry section. The turning angle can be defined as the local rotation of the blank sheet, i.e., this angle is

\footnotetext{
${ }^{1}$ M\&M Research, Inc. http://www.m-research.co.jp.
} 


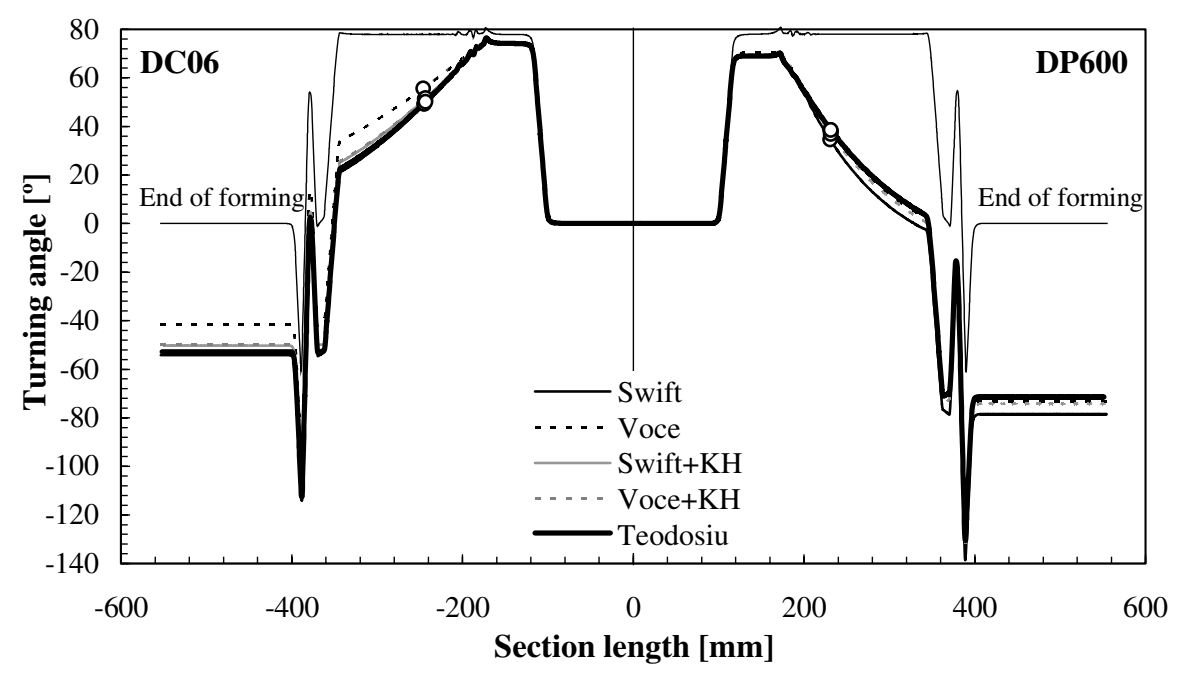

Fig. 5. Evolution of the turning angle along the middle symmetry section as predicted by each constitutive model for DC06 and DP600 steels. The symmetry plane defines the zero coordinate for the section length. The evolution of the turning angle at the end of the forming phase is shown as reference.

calculated by measuring the angle between two consecutive nodes of the symmetry section and its horizontal alignment (Kase et al., 1999). The evolution of the turning angle at the end of the forming phase (before springback) is presented as reference. This reference is used to determine the evolution of the springback angle along the symmetry section, as presented in Fig. 6. The springback angle is defined as the difference between the turning angles before and after unloading. At the top of the punch the springback angle is close to zero. Then it slightly increases along the punch radius. Notice that the turning angle never

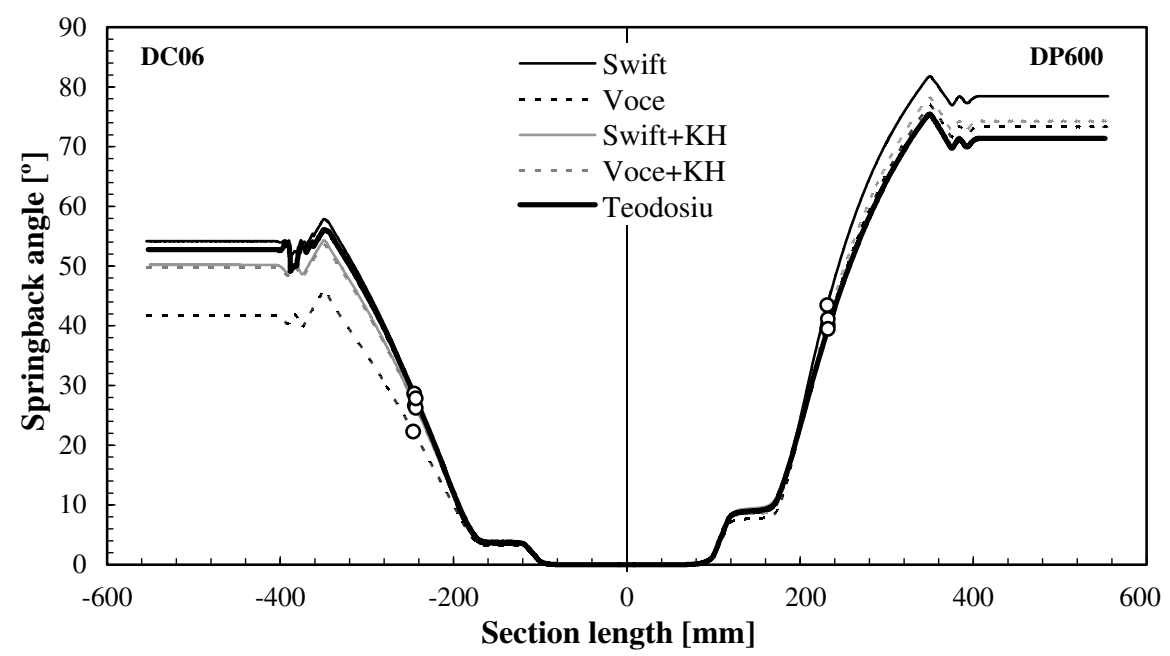

Fig. 6. Evolution of the springback angle along the middle symmetry section as predicted by each constitutive model for DC06 and DP600 steels. The symmetry plane defines the zero coordinate for the section length. 
reaches the value of $90^{\circ}$ due to the large gap between the punch and the die (see Fig. 1). On the vertical wall the springback angle is constant between a section length of approximately $120 \mathrm{~mm}$ and $200 \mathrm{~mm}$. After this, the springback angle starts to increase and the differences due to the constitutive modeling become observable. Between section lengths of about $350-400 \mathrm{~mm}$ the evolution of either the turning angle or the springback angle change dramatically due to the geometrical variations imposed by the drawbead. Finally, the springback angle remains almost constant in the undeformed flange. Fig. 6 also shows that the flange springback angle is strongly associated with the springback angle of the vertical wall. The flange springback angle can be understood as the integration of the incremental springback angles along the aforesaid section.

In order to compare the predicted springback, three geometrical parameters were selected: the channel sidewall angle and radius, as defined in Fig. 4, and the flange springback angle, evaluated according to Fig. 6. The sidewall curl radius is difficult to evaluate due to its variation along the sidewall. Therefore, one point of the sidewall was selected in order to determine its curl radius: its position is highlighted in Fig. 6. The sidewall angle changes due to springback. However, only the material in contact with the punch radius, which was submitted only to bending, contributes to this evolution. On the other hand, the sidewall curl radius is measured in a region of the blank sheet that has been drawn over the drawbead and die radii and which has undergone several cycles of bending/unbending and stretching. The three geometrical parameters are summarized in Table 4 for both materials and all constitutive models. The differences in the sidewall angle are small, for both steels. Taking as reference the result attained using the Swift law, the difference in the sidewall angle predicted by the various work-hardening models is less than $1 \%$ and $1.5 \%$ for the DC06 and the DP600 steels, respectively. For both steels the higher springback angle is predicted by the Swift law. Such a result can be associated with the Bauschinger effect, which reduces the flow stress after a strain-path reversal. If the kinematic hardening, and thus the Bauschinger effect, is not taken into account, the springback angles are typically over-predicted ( $\mathrm{Li}$ et al., 2002a). With reference to the springback angle, the numerical result scattering for all constitutive models is smaller than $10 \%$ and $25 \%$, in cases of DP600 and DC06 steels, respectively. However, if the Voce result is eliminated in case of DC06 steel, the numerical result scattering is only about $8 \%$. It is possible to link the variations between the sidewall curl radius and the springback angle: a lower flange springback angle corresponds to a higher sidewall curl radius. As for the draw-bend test

Table 4

Springback angle and sidewall geometrical parameters predicted with each constitutive model for both DC06 and DP600 steels

\begin{tabular}{|c|c|c|c|c|c|c|}
\hline \multirow[t]{3}{*}{ Constitutive model } & \multicolumn{3}{|l|}{ DC06 } & \multicolumn{3}{|l|}{ DP600 } \\
\hline & \multirow{2}{*}{$\begin{array}{l}\text { Flange } \\
\text { Springback angle }\end{array}$} & \multicolumn{2}{|c|}{ Sidewall } & \multirow{2}{*}{$\begin{array}{l}\text { Flange } \\
\text { Springback angle }\end{array}$} & \multicolumn{2}{|c|}{ Sidewall } \\
\hline & & Angle & $\begin{array}{l}\text { Curl radius } \\
(\mathrm{mm})\end{array}$ & & Angle & $\begin{array}{l}\text { Curl radius } \\
(\mathrm{mm})\end{array}$ \\
\hline Swift law & $54.2^{\circ}$ & $74.5^{\circ}$ & 114.1 & $78.5^{\circ}$ & $69.3^{\circ}$ & 76.7 \\
\hline Voce law & $41.7^{\circ}$ & $74.7^{\circ}$ & 175.5 & $73.3^{\circ}$ & $70.3^{\circ}$ & 83.1 \\
\hline Swift law + KH & $50.2^{\circ}$ & $74.1^{\circ}$ & 135.6 & $71.6^{\circ}$ & $68.6^{\circ}$ & 96.6 \\
\hline Voce law $+\mathrm{KH}$ & $49.8^{\circ}$ & $74.2^{\circ}$ & 135.3 & $74.3^{\circ}$ & $69.5^{\circ}$ & 83.9 \\
\hline Teodosiu & $52.7^{\circ}$ & $74.2^{\circ}$ & 122.5 & $71.4^{\circ}$ & $69.1^{\circ}$ & 94.2 \\
\hline
\end{tabular}


geometry (Papeleux and Ponthot, 2002; Li et al., 2002a), the springback angle of the flange is mainly a function of the component angle corresponding to the sidewall curl.

Despite the fact that for both steels higher springback angles are attained with the Swift law, there is no other common behavior in the comparison of the results obtained from the several work-hardening models. Although the Voce law clearly gives a different result in case of the DC06 steel, the same is not true in case of DP600 steel. For this latter steel, the springback angle predicted by the Voce law with kinematic hardening is very close to the ones obtained with the pure isotropic work-hardening models, namely the Swift and Voce laws. It is also interesting to note the difference between the results obtained with the Voce law with kinematic hardening and Teodosiu's, bearing in mind the similarities in the formulation of these two constitutive models. Finally, for the DC06 steel, all simulations carried out with kinematic hardening show very similar results with regard to springback prediction.

\subsubsection{Strain-path change analysis}

During the forming process the blank sheet flows through the drawbead and die radius, and is submitted to several tension-compression cycles. In order to evaluate these cycles two material points were selected in the middle symmetry section, one in the upper surface $(z=1)$ and other in the lower surface $(z=0)$ of the blank sheet. These points were selected so that, during the forming process, the cross-section between them flows through the drawbead and die radius. At the end of the forming process the studied points are positioned on the vertical sidewall. For each time increment the amount $\mathbf{N}: \mathbf{N}_{\text {ref }}$ is calculated. $\mathbf{N}$ is an objective second-order tensor defining the normal to the yield surface. It evolves during the forming process since $\mathbf{N}$ is computed from the incremental plastic strain tensor, which for a given material point evolves continuously as a function of the strain-path. $\mathbf{N}_{\text {ref }}$ is a reference direction of the plastic strain rate tensor, theoretically associated with plane strain tension along transverse direction. $\mathbf{N}_{\text {ref }}$ does not change during the deformation process since it is defined in the objective frame. Therefore, the amount $\mathbf{N}: \mathbf{N}_{\text {ref }}$ can be used to evaluate the strain-path changes during the forming process, as well as to find out the current strain-path: $\mathbf{N}: \mathbf{N}_{\text {ref }}$ becomes close to 1 in plane strain tension and -1 in plane strain compression. Since $\mathbf{N}$ is only defined if the increment is elastoplastic, $\mathbf{N}: \mathbf{N}_{\text {ref }}$ is only computed if the increment of equivalent plastic strain is different from zero.

Fig. 7 presents the history of the amount $\mathbf{N}: \mathbf{N}_{\text {ref }}$ with reference to punch displacement, for the selected material points. In order to simplify the analysis, Fig. 7 includes several pictures labeled from (a) to (k). These pictures show several instantaneous positions of the studied points during the forming process. For a punch displacement of approximately $78 \mathrm{~mm}$ these points begin to present some plasticity due to the bending imposed by the drawbead (Fig. 7(a)). Fig. 7 highlights four strain-path changes for the material points moving along the drawbead and the die radius. The strain-path changes occur at punch displacements of approximately 92, 104, 114 and $141 \mathrm{~mm}$, corresponding to the superposed pictures (c), (e), (g) and (k). The other superposed pictures show positions for which the cross-section enters an elastic domain due to: (i) the gap between the drawbead radius and the drawbead channel length (see (b) and (f)); (ii) the drawbead's nose (see (d)); (iii) the plane surface between the drawbead and the die radius (see (h)); (iv) the die radius (see (j)). The analysis of Fig. 7 also confirms that these tension-compression cycles are inverted for points located in the upper and lower surfaces of the blank sheet. 


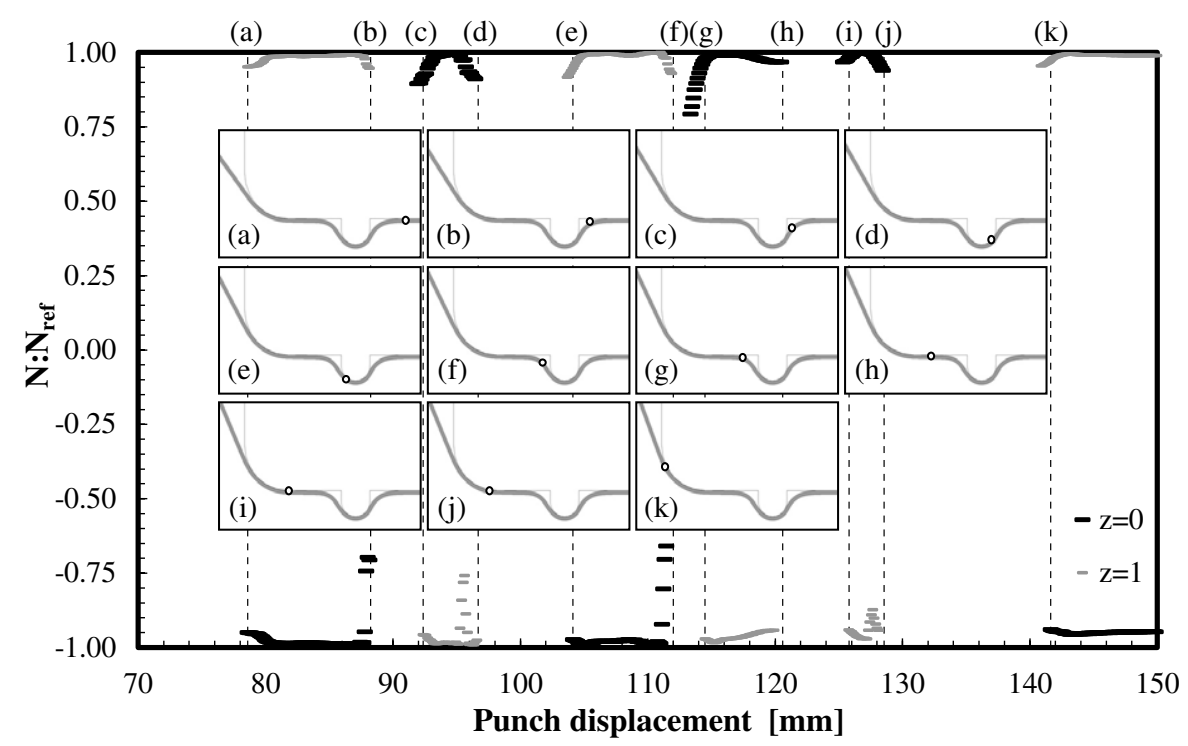

Fig. 7. Tension-compression cycles for a point located on the upper surface of the blank sheet $(z=1)$ and a point located on the lower surface of the blank sheet $(z=0)$. The superposed pictures ((a) to (k)) show the instantaneous position of the studied points during the forming process. Both points are in the same cross section.

\subsubsection{Internal state variables analysis}

The material points located in the upper and lower surface of the blank attain similar values of equivalent plastic strain at the end of the forming process. Fig. 8 shows the distribution of equivalent plastic strain along the lower surface of the symmetry section, for both materials. As expected, no material points close to the top of the punch exhibit any plastic strain. The punch radius induces some plasticity but then there is again some material without any plastic strain. This material was initially located in the gap between the punch and the die, which explains the zero value of equivalent plastic strain (see Fig. 1). After a section length of about $170 \mathrm{~mm}$ the equivalent plastic strain increases rapidly. This rapid increase occurs up to a section length of about $200 \mathrm{~mm}$ and is associated with the material that flowed only through the die radius. Such material corresponds to the section length for which the change of springback angle on the vertical sidewall starts to occur. Then, the equivalent plastic strain attains a constant maximum value, corresponding to the material that was submitted to cyclic bending in the drawbead and the die radius. The different work-hardening models give approximately the same equivalent plastic strain evolution. However, the maximum equivalent plastic strain attained is higher for the DC06 steel than for the DP600 steel, being 66\% and 54\%, respectively (see Fig. 8).

A similar analysis was carried out concerning the equivalent tensile stress $\bar{\sigma}$. In spite of its similarity to the overall behavior of the equivalent plastic strain (similar values of equivalent plastic stress are attained in material points located on the upper and lower surfaces of the blank sheet), its magnitude is particularly dependent on the work-hardening model. For both steels, the constitutive model that attains the highest equivalent tensile stress in the vertical sidewall is the Swift Law, which seems to confirm its over-prediction of springback. However, for the other work-hardening models no correlation can be found 


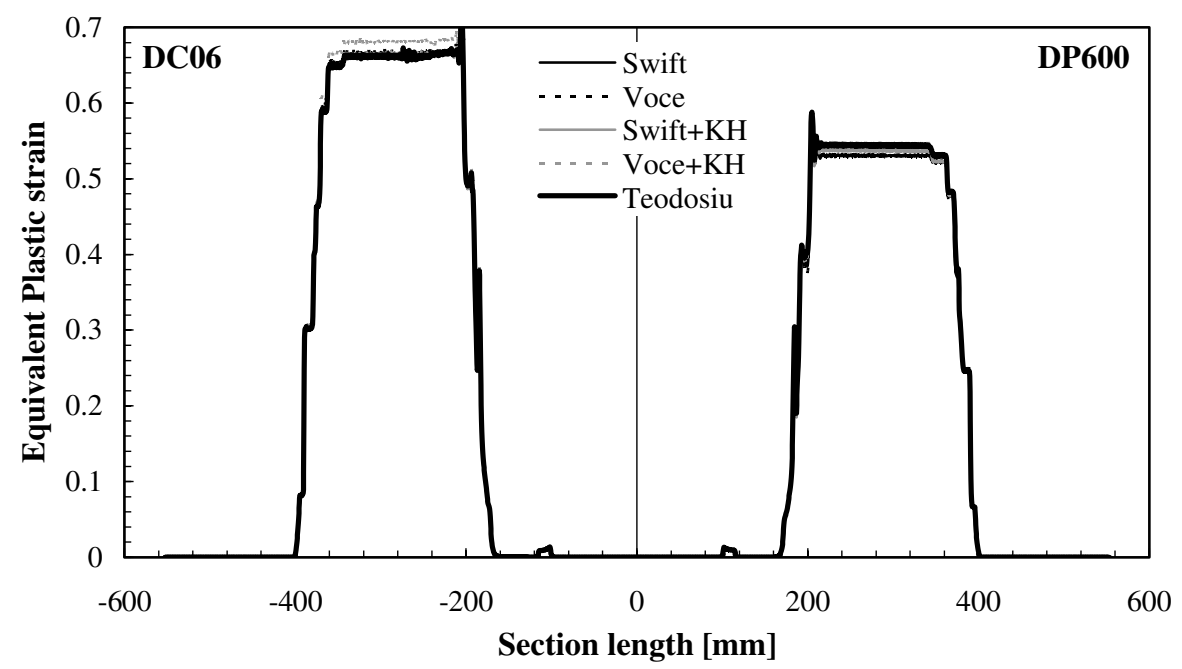

Fig. 8. Evolution of the equivalent plastic strain along the middle symmetry section as predicted by each constitutive model for DC06 and DP600 steels. The symmetry plane defines the zero coordinate for the section length.

between the final equivalent tensile stress distribution and the predicted springback of the flange.

The springback phenomenon seems to depend basically on the through-thickness stress gradients. To highlight this dependency the through-thickness distribution of the most relevant component of the stress tensor is presented in Figs. 9 and 10 for the DC06 and DP600 steels, respectively, just before unloading. In the proposed numerical example the main strain-path is along the $O x$ direction, corresponding to the transverse direction

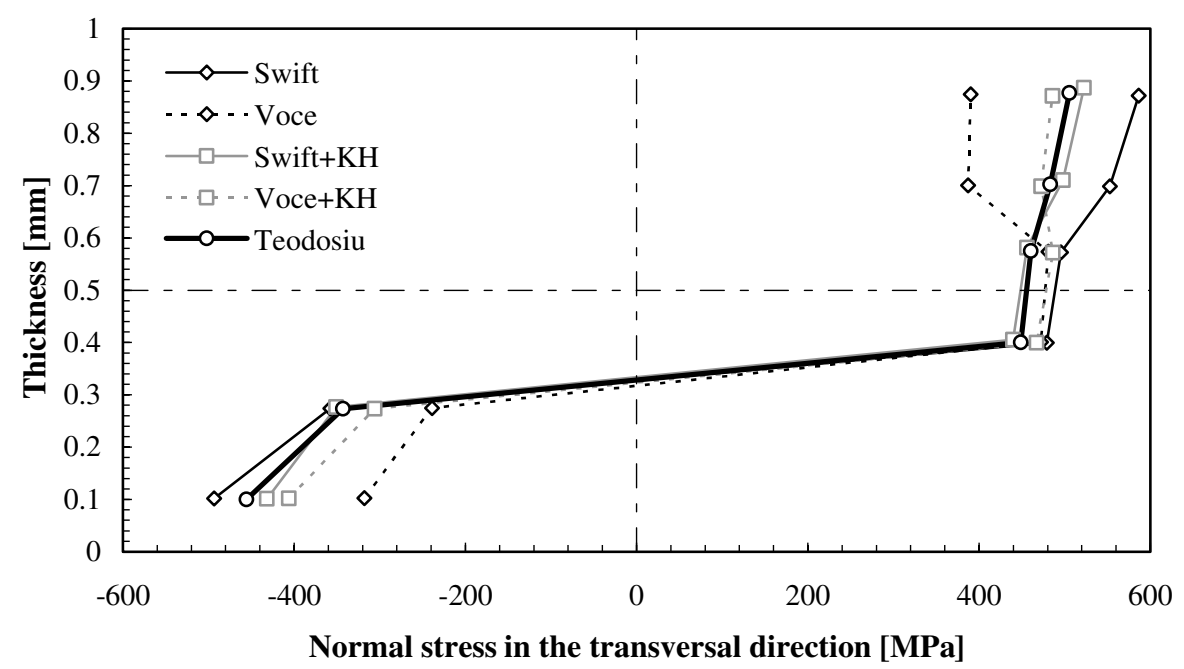

Fig. 9. DC06: distribution of the normal stresses at gauss points located between points $z=0$ and $z=1$. 


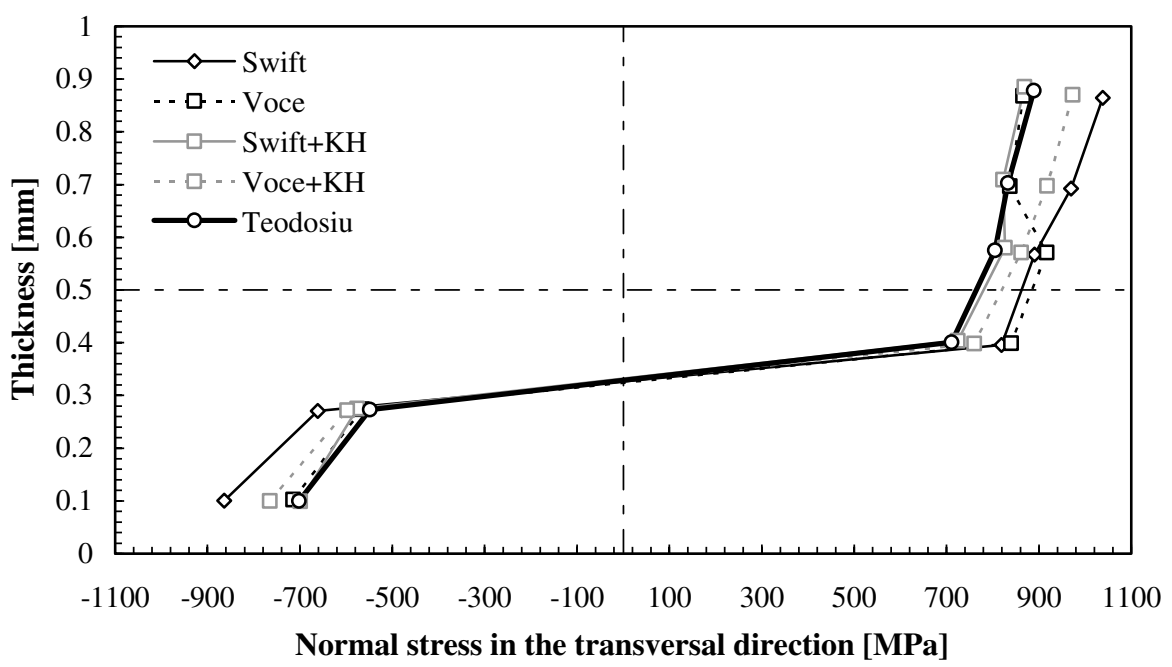

Fig. 10. DP600: distribution of the normal stresses at gauss points located between points $z=0$ and $z=1$.

in the original material's frame. Hence, from the point of view of springback, the main component of the stress tensor defined in the objective frame is the normal stress along the transverse direction. The studied section corresponds to the cross-section between the aforementioned material points defined at $z=0$ and $z=1$; its final position in the final formed part is the point defined to evaluate the sidewall curl radius. The same stress gradient occurs in the vertical sidewall, not only for the studied cross-section but for all material points that flowed through the drawbead and the die radius. By analyzing the stress distributions along the sheet thickness, at the selected section, it is possible to correlate the simulated flange springback angle with the stress gradient's through-thickness just before unloading. For the DC06 steel the Swift law clearly leads to the highest gradient followed by Teodosiu, Swift and Voce combined with kinematic hardening and, finally, the Voce law with the lowest gradient. For the DP600 steel, once again, the maximum gradient is attained with the Swift law, followed by Voce law combined with kinematic hardening and Voce law. Teodosiu's model and Swift combined with kinematic hardening present the lowest gradients through thickness for the DP600 steel. To summarize, smaller through-thickness stress gradients are usually associated with smaller springback effects.

As shown, the springback angle of the flange is mainly dictated by the through-thickness stress gradients of the material submitted to successive tension-compression cycles. The differences in the through-thickness stress gradients obtained with the different work-hardening models cannot be accurately predicted without taking into account the tension-compression cycles. These differences result from the strain induced in each of the tension-compression cycles. Different prestrain levels in each cycle can lead to a different trend in the comparison of work-hardening models. To highlight this conclusion, a three-point bending test was simulated with DD3IMP code for all work-hardening models, for both materials. This test was performed up to a maximum level of equivalent plastic strain similar to the one attained by the material located in the vertical wall of the U-shape channel. The three-point bending test was used to impose bending/unbending trajectories similar to the ones identified in the U-shape channel. Figs. 11 and 12 present 


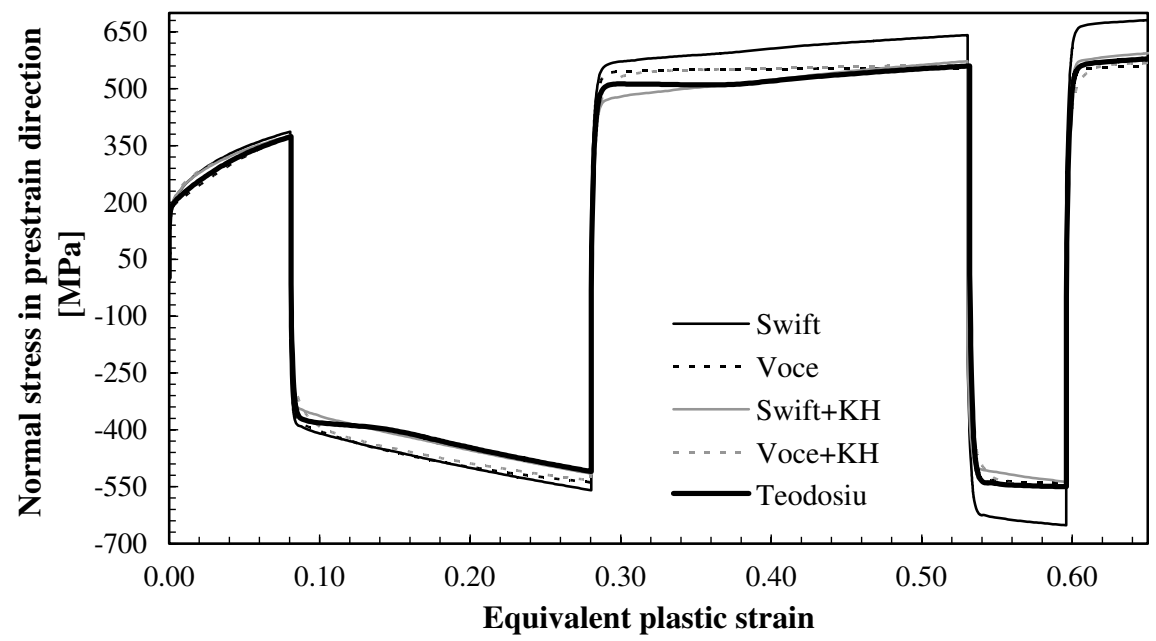

Fig. 11. DC06: normal stress evolution for a bending/unbending trajectory as predicted by the different constitutive models.

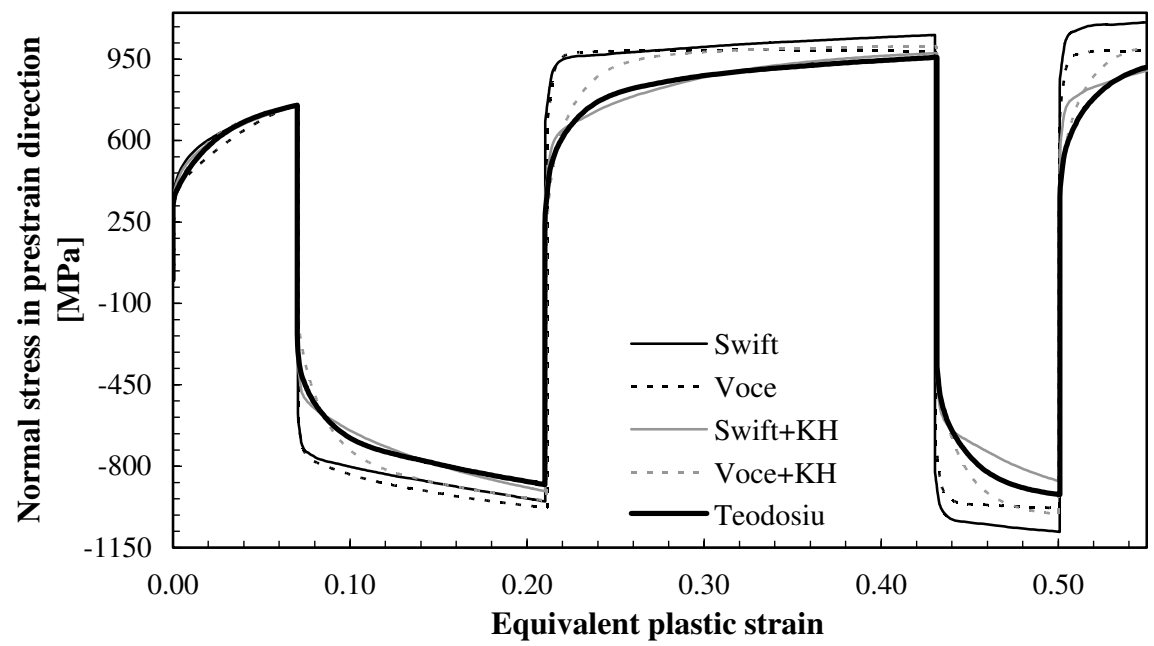

Fig. 12. DP600: normal stress evolution for a bending/unbending trajectory as predicted by the different constitutive models.

the normal stress evolution in the prestrain direction obtained with the different workhardening models for the bending/unbending trajectories for both DC06 and DP600 steels, respectively. This test represents the same type of strain-path changes identified in the U-shape channel. However, in this case the strain-path change occurs to a fixed equivalent plastic strain value for all work-hardening laws. In the U-shape channel there are slight differences in the equivalent plastic strain obtained for each work-hardening model (see Fig. 8). Nevertheless, for the levels of equivalent plastic strain attained at the end of the forming process it is possible to check that a correlation exists between 
the stress gradients predicted and those that result in the springback angles shown in Table 4. For the DC06 steel the highest stress gradient is clearly obtained with the Swift law followed by Swift combined with kinematic hardening, Teodosiu, Voce combined with kinematic and, finally, Voce law. For the DP600 steel, once more, the highest stress gradient is attained by the Swift law, followed by Voce combined with kinematic hardening, Voce, Teodosiu and Swift combined with kinematic hardening. There are some slight differences in the stress gradients predicted by the three-point bending test and by the U-shape channel forming test. However, it is important to notice that the bending/unbending test imposes a through-thickness stress gradient symmetrical to the middle thickness line, since the stretching effect is not being considered. In the U-shape channel the tension-compression cycles result from the bending and unbending along the drawbead and die radii combined with tensile forces that result from the restraining imposed by the drawbead and punch displacement. This leads to a neutral line position below the middle thickness line as shown in Fig. 9 for the DC06 and in Fig. 10 for the DP600, resulting in a non-symmetrical stress gradient.

Globally, the tensile stresses predicted in the bending/unbending test are very similar for both the Swift combined with kinematic hardening and the Teodosiu model, confirming that for both steels the Bauschinger effect is similarly described by both models. However, Teodosiu's microstructural model describes the work-hardening stagnation followed by resumption after a reversed strain-path change more accurately, in particular for the DC06 steel. This may justify the 5\% difference in springback angle of the flange of the U-shape rail for DC06 steel, obtained when comparing Swift law combined with kinematic hardening and Teodosiu's model (Table 4). In case of DP600 steel this difference is of $0.3 \%$. The results for the three-point bending test confirm the importance not only of the strain-path but also of the strain attained at each strain-path change. In fact, even for these two work-hardening models the differences in stress gradient can be higher if other levels of equivalent plastic prestrain are considered. The results of the bending/ unbending curves also allow confirmation that the differences between the work-hardening models are more important in processes that involve abrupt strain-path changes, as already stated by Li et al. (2003). Moreover, it gives some insight into the reason why a global trend does not exist for work-hardening models: one model can predict larger springback angles for some materials and smaller for other materials as reported here and also by Haddag et al. (2005). This fact results from the through-thickness stress gradient that is induced by the strain level attained in each strain-path that is differently predicted by the various work-hardening models.

\section{Conclusions}

In this study several work-hardening models were evaluated in order to determine their influence on the numerical prediction of the springback phenomenon. Constitutive parameters identification was performed based on an appropriate set of experimental data (Haddadi et al., 2006). In general, the springback results show some sensitivity to the work-hardening modeling. However, despite the high levels of equivalent plastic strain attained in the formed U-shape channel, this study shows that even in this case the differences in springback prediction are not significantly higher than those reported in previous studies, for which the equivalent plastic strain levels were clearly lower than in the present case (Chaparro et al., 2004; Bouvier et al., 2005). Nevertheless, the differences between the 
results obtained with the studied work-hardening models exist and they can, without any doubt, be associated with the predicted through-thickness stress gradients.

The strain-path changes identified in the U-shape channel allow the springback tendency to be predicted by a bending/unbending test. These simple test results confirm that not only are strain-path changes themselves important but also the strain attained by each strain-path, explaining why there is no global trend for the work-hardening models under study. One model can predict larger springback angles for some materials and smaller for other ones according to the predominant strain-paths and strain-path changes. Also, by comparing the influence of the work-hardening models on springback, different trends can be expected depending on the selected sheet metal formed part as well as the process conditions.

\section{Acknowledgements}

The authors are grateful to The Portuguese Foundation for Science and Technology (FCT) who financially supported this study, through the Program POCTI (Portuguese Government and FEDER).

\section{References}

Alves, J.L., Menezes, L.F., 2001. Application of tri-linear and tri-quadratic 3-D solid finite elements in sheet metal forming simulations. In: Mori, K.-I. (Ed.), Proceedings of the Numiform'01 on Simulation of materials processing: Theory, Methods and Applications. Balkema, Rotterdam, pp. 639-644.

Alves, J.L., Oliveira, M.C., Menezes, L.F., 2004a. An advanced constitutive model in sheet metal forming simulation: the Teodosiu microstructural model and the Cazacu Barlat yield criterion. In: Glosh, S., Castro, J.C., Lee, J.K. (Eds.), Proceedings of the Numiform'04 on Materials Processing and Design: Modelling, Simulation and Applications, Amer Inst Physics, Melville, p. 1645.

Alves, J.L., Oliveira, M.C., Menezes, L.F., 2004b. Springback evaluation with several phenomenological yield criteria. Mater. Sci. Forum 455-456, 732-736.

Alves, J.L., Oliveira, M.C., Menezes, L.F., 2005. Drawbeads: to be or not to be. In: Cao, J., Shi, M.F., Stoughton, T.B., Wang, C.T., Zhang, L. (Eds.), Proceedings of Numisheet'05 6th International Conference and Workshop on Numerical Simulation of 3D Sheet Forming Processes: On the Cutting Edge of Technology, Part A, Amer Inst Physics 778, Melville, pp. 655-660.

Alves, J.L., Oliveira, M.C., Menezes, L.F., 2006. Numerical evaluation of the influence of the elastic properties evolution in springback prediction. In: Santos, A.D., Barata da Rocha, A., (Eds.), Proceedings of IDDRG'06 Conference of the International Deep Drawing Research Group: Drawing the Things to Come, Trends and Advances in Sheet Metal Forming, INEGI, Porto, pp. 161-168.

Areias, P.M.A., César de Sá, J.M.A., Conceição António, C.A., Fernandes, A.A., 2003. Analysis of 3D problems using a new enhanced strain hexahedral element. Int. J. Numer. Meth. Eng. 58 (11), 1382-1637.

Barlat, F., Lege, D.J., Brem, J.C., 1991. A six-component yield function for anisotropic materials. Int. J. Plasticity 7 (7), 693-712.

Bouvier, S., Teodosiu, C., Maier, C., Banu, M., Tabacaru, V., 2001. Selection and identification of elastoplastic models for the materials used in the benchmarks, WP3, Task 1, 18-Months Progress Report of the Digital Die Design Systems (3DS), IMS 1999000051.

Bouvier, S., Alves, J.L., Oliveira, M.C., Menezes, L.F., 2005. Modelling of anisotropic work-hardening behaviour of metallic materials subjected to strain path changes. Comput. Mater. Sci. 32 (3-4), 301-315.

Buranathiti, T., Cao, J., 2005. Benchmark Simulation Results: Channel Draw/Cylindrical Cup 2-Stage Test (Benchmark 3). In: Proceedings of Numisheet'05 6th International Conference and Workshop on Numerical Simulation of 3D Sheet Forming Processes: On the Cutting Edge of Technology, Part B, Amer Inst Physics 778, Melville, pp. 1121-1133.

Carden, W.D., Geng, L.M., Matlock, D.K., Wagoner, R.H., 2002. Measurement of springback. Int. J. Mech. Sci. 44 (1), 79-101. 
Cazacu, O., Barlat, F., 2001. Generalization of Drucker's yield criterion to orthotropic. Math. Mech. Solids 6 (6), 613-630.

Chaparro, B.M., Oliveira, M.C., Alves, J.L., Menezes, L.F., 2004. Work hardening models and the numerical simulation of the deep drawing process. Mater. Sci. Forum 455-456, 717-722.

Choi, Y., Han, C.-S., Lee, J.K., Wagoner, R.H., 2006a. Modeling multi-axial deformation of planar anisotropic elasto-plastic materials, part I: Theory. Int. J. Plasticity 22 (9), 1745-1764.

Choi, Y., Han, C.-S., Lee, J.K., Wagoner, R.H., 2006b. Modeling multi-axial deformation of planar anisotropic elasto-plastic materials, part II: Applications. Int. J. Plasticity 22 (9), 1765-1783.

Clausen, A.H., Hopperstad, O.S., Langseth, M., 2001. Sensitivity of model parameters in stretch bending of aluminium extrusions. Int. J. Mech. Sci. 43 (2), 427-453.

Cleveland, R.M., Ghosh, A.K., 2002. Inelastic effects on springback in metals. Int. J. Plasticity 18 (5-6), 769-785.

Courvoisier, L., Martiny, M., Ferron, G., 2003. Analytical modelling of drawbeads in sheet metal forming. J. Mater. Process Technol. 133 (3), 359-370.

Gau, J.-T., Kinzel, G.L., 2001. A new model for springback prediction in which the Bauschinger effect is considered. Int. J. Mech. Sci. 43 (8), 1813-1832.

Geng, L., Wagoner, R.H., 2002. Role of plastic anisotropy and its evolution on springback. Int. J. Mech. Sci. 44 (1), 123-148.

Geng, L., Shen, Y., Wagoner, R.H., 2002. Anisotropic hardening equations derived from reverse-bend testing. Int. J. Plasticity 18 (5-6), 743-767.

Haddadi, H., Bouvier, S., Banu, M., Maier, C., Teodosiu, C., 2006. Towards an accurate description of the anisotropic behaviour of sheet metals under large plastic deformations: modelling, numerical analysis and identification. Int. J. Plasticity 22 (12), 2226-2271.

Haddag, B., Balan, T., Abed-Meraim, F., 2005. Springback simulation: impact of some advanced constitutive models and numerical parameters. In: Cao, J., Shi, M.F., Stoughton, T.B., Wang, C.T., Zhang, L. (Eds.). Proceedings of Numisheet'05 6th International Conference and Workshop on Numerical Simulation of 3D Sheet Forming Processes: On the Cutting Edge of Technology, Part B, Amer Inst Physics 778, Melville, pp. 289-291.

Hill, R., 1948. A theory of the yielding and plastic flow of anisotropic materials. Proceedings of the Royal Society of London Series A-Mathematical, Physical and Engineering Science 193 (1033), 281-297.

Hiwatashi, S., Van Bael, A., Van Houtte, P., Teodosiu, C., 1997. Modelling of plastic anisotropy based on texture and dislocation structure. Comput. Mater. Sci. 9 (1-2), 274-284.

Hiwatashi, S., Van Bael, A., Van Houtte, P., Teodosiu, C., 1998. Prediction of forming limit strains under strainpath changes: application of an anisotropic model based on texture and dislocation structure. Int. J. Plasticity 17 (7), 647-669.

Hughes, T.J.R., 1980. Generalization of selective integration procedures to anisotropic and nonlinear. Int. J. Numer. Meth. Eng. 15, 1413-1418.

Jiao, Z.-P., Li, C., 2000. A new formulation of eight-node hexagonal solid element. Comput. Meth. Appl. Mech. Eng. 187 (1-2), 213-217.

Karafillis, A.P., Boyce, M.C., 1993. A general anisotropic yield criterion using bounds and a transformation weighting tensor. J. Mech. Phys. Solids 41 (12), 1859-1886.

Kase, K., Makinouchi, A., Nakagawa, T., Suzuki, H., Kimura, F., 1999. Shape error evaluation method of freeform surfaces. Comput. Aided Des. 31 (8), 495-505.

Kawka, M., Kakita, T., Makinouchi, A., 1998. Simulation of multi-step sheet metal forming processes by a static explicit FEM code. J. Mater. Process Technol. 80-81, 54-59.

Kyriakides, S., Corona, E., Miller, J.E., 2004. Effect of yield surface evolution on bending induced cross sectional deformation of thin-walled sections. Int. J. Plasticity 20 (4-5), 607-618.

Lee, S.W., Yang, D.Y., 1998. An assessment of numerical parameters influencing springback in explicit finite elements analysis of sheet metal forming process. J. Mater. Process. Technol. 80-81, 60-67.

Lee, S.W., Yoon, J.W., Yang, D.Y., 1999. Comparative investigation into the dynamic explicit and the static implicit method for springback of sheet metal stamping. Eng Computation 16 (2-3), 347-373.

Lee, M.-G., Kim, D., Kim, C., Wenner, M.L., Chung, K., 2005. Spring-back evaluation of automotive sheets based on isotropic-kinematic hardening laws and non-quadratic anisotropic yield functions, part III: applications. Int. J. Plasticity 21 (5), 915-953.

Lemaître, J., Chaboche, J.-L., 1985. Mechanics of Solid Materials. Cambridge University Press, Cambridge.

Leu, D.-K., 1997. A simplified approach for evaluating bendability and springback in plastic bending of anisotropic sheet materials. J. Mater. Process. Technol. 66 (1-3), 9-17. 
Li, K.P., Carden, W.P., Wagoner, R.H., 2002a. Simulation of springback. Int. J. Mech. Sci. 44 (1), 103-122.

Li, X., Yang, Y., Wang, Y., Bao, J., Li, S., 2002b. Effect of the material-hardening mode on the springback simulation accuracy of V-free bending. J. Mater. Process. Technol. 123 (2), 209-211.

Li, S., Hoferlin, E., Van Bael, A., Van Houtte, P., Teodosiu, C., 2003. Finite element modelling of plastic anisotropy induced by texture and strain-path change. Int. J. Plasticity 19 (5), 647-674.

McMeeking, R.M., Rice, J.R., 1975. Finite element formulation for problems of large elastoplastic deformation. Int. J. Solids Struct. 11, 601-615.

Meinders, T., Carleer, B.D., Geijselaers, H.J.M., Huétink, J., 1998. The implementation of an equivalent drawbead model in a finite element code for sheet metal forming. J. Mater. Process. Technol. $83(1-3), 234$ 244.

Menezes, L.F., Teodosiu, C., 2000. Three-dimensional numerical simulation of the deep-drawing process using solid finite element. J. Mater. Process. Technol. 97 (1-3), 100-106.

Menezes, L.F., Teodosiu, C., Makinouchi, A., 1991. 3-D solid elasto-plastic elements for simulating sheet metal forming processes by the finite element method. In: VDI Berichte (Eds.), Proceedings FE-simulation of 3-D Sheet Metal Forming Processes in Automotive Industry, vol. 864, pp. 381-403.

Menezes, L.F., Thuillier, S., Manach, P.Y., Bouvier, S., 2002. Influence or work hardening models on the numerical simulation of a reverse deep drawing process. In: Khan, A.S., Lopez Pamies, O.L. (Eds.), Proceedings of Plasticity'02 Plasticity, Damage and Fracture at Macro, Micro and Nanoscales. Neat Press Fulton, Maryland, pp. 331-333.

Morestin, F., Boivin, B., 1996. On the necessity of taking into account the variation in the Young modulus with plastic strain in elastic-plastic software. Nucl. Eng. Des. 162 (1), 107-116.

Narasimhan, N., Lovell, M., 1999. Predicting springback in sheet metal forming: an implicit to implicit sequential solution procedure. Finite Elem. Anal. Des. 33 (1), $29-42$.

Nine, H.D., 1978. Drawbead Forces in Sheet Metal FormingMechanics of Sheet Metal Forming. Plenum Press, New York, pp. 179-211.

Oliveira, M.C., Alves, J.L., Menezes, L.F., 2002. Springback Evaluation using 3-D Finite Elements. In: Yang, D.Y., Oh, S.I., Huh, H., Kim, Y.H. (Eds.), Proceedings of Numisheet'02 5th International Conference and Workshop on Numerical Simulation of 3D Sheet Forming Processes: Verification of Simulation with Experiment, vol. 1, pp. 189-194.

Oliveira, M.C., Alves, J.L., Menezes, L.F., 2003a. Improvement of a frictional contact algorithm for strongly curved contact problems. Int. J. Numer. Meth. Eng. 58 (14), 2083-2101.

Oliveira, M.C., Alves, J.L., Menezes, L.F., 2003b. One step springback strategies in sheet metal forming. In: Owen, D.R.J., Oñate, E., Suárez, B. (Eds.), Proceedings of Complas'02 VII International Conference on Computational Plasticity - Fundamentals and Applications. International Center for Numerical Methods in Engineering, Barcelona, p. 87.

Oliveira, M.C., Baptista, A.J., Alves, J.L., Menezes, L.F., Green, D.E., Gnaeupel-Herold, T., Iadicola, M.A., Foecke, T., Stoughton, T.B., 2006. Two stage forming: experimental and FE analysis. In: Santos, A.D., Barata da Rocha, A. (Eds.), Proceedings of IDDRG'06 Conference of the International Deep Drawing Research Group: Drawing the things to come, Trends and Advances in Sheet Metal Forming, INEGI, Porto, pp. 279-286.

Papeleux, L., Ponthot, J.-P., 2002. Finite element simulation of springback in sheet metal forming. J. Mater. Process. Technol. 125-126, 785-791.

Peeters, B., Hoferlin, E., Van Houtte, P., Aernoudt, E., 2001a. Assessment of crystal plasticity based calculation of the lattice spin of polycrystalline metals for FE implementation. Int. J. Plasticity 17 (6), 819-883.

Peeters, B., Seefeldt, M., Teodosiu, C., Kalidindi, S.R., Van Houtte, P., Aernoudt, E., 2001b. Work-hardening/ softening behaviour of B.C.C. polycrystals during changing strain paths: I. An Integrated model based on substructure and texture evolution, and its prediction of the stress-strain behaviour of an IF steel during twostage strain paths. Acta Mater. 49 (9), 1607-1619.

Peeters, B., Seefeldt, M., Teodosiu, C., Kalidindi, S.R., Van Houtte, P., Aernoudt, E., 2001c. Work-hardening/ softening behaviour of B.C.C. polycrystals during changing strain paths: II. TEM Observations of dislocation sheets in an IF steel during two-stage strain paths and their representation in terms of dislocation densities. Acta Mater. 49 (9), 1621-1632.

Peeters, B., Kalidindi, S.R., Teodosiu, C., Van Houtte, P., Aernoudt, E., 2002. A theoretical investigation of the influence of dislocation sheets on evolution of yield surfaces in single-phase B.C.C. polycrystals. J. Mech. Phys. Solids 50 (4), 783-807. 
Reese, S., 2005. On a physically stabilized one point finite element formulation for three-dimensional finite elastoplasticity. Comput. Meth. Appl. Mech. Eng. 194 (45-47), 4685-4715.

Samuel, M., 2002. Influence of drawbead geometry on sheet metal forming. J. Mater. Process. Technol. 122, 94 103.

Shi, M.F., Huang, M., 2005. Specification for benchmark materials. In: Cao, J., Shi, M.F., Stoughton, T.B., Wang, C.T., Zhang, L. (Eds.). Proceedings of Numisheet'05 6th International Conference and Workshop on Numerical Simulation of 3D Sheet Forming Processes: On the Cutting Edge of Technology, Part B, Amer Inst Physics 778, Melville, pp. 1173-1178.

Stoughton, T.B., Yoon, J.W., 2006. Review of Drucker's postulate and the issue of plastic stability in metal forming. Int. J. Plasticity 22 (3), 391-433.

Stoughton, T., Green, D., Iadicola, M., 2005. Specification for BM3: two-stage channel/cup draw. In: Cao, J., Shi, M.F., Stoughton, T.B., Wang, C.T., Zhang, L. (Eds.), Proceedings of Numisheet'05 6th International Conference and Workshop on Numerical Simulation of 3D Sheet Forming Processes: On the Cutting Edge of Technology, Part B, Amer Inst Physics 778, Melville, pp. 1157-1172.

Teodosiu, C., 1989. The plastic spin: microstructural origin and computational significance. In: Owen, D.R.J., Hinton, E., Oñate, E. (Eds.), Proceedings of 2nd International Conference on Computational Plasticity, p. 163.

Teodosiu, C., Hu, Z., 1995. Evolution of the intragranular microstructure at moderate and large strains: modelling and computational significance. In: Shen, S., Dawson, P.R. (Eds.), Proceedings of the Numiform'95 on Simulation of Materials Processing: Theory, Methods and Applications. Balkema, Rotterdam, pp. 173182.

Teodosiu, C., Hu, Z., 1998. Microstructure in the continuum modelling of plastic anisotropy. In: Riso National Laboratory (Eds.), Proceedings of the 19th Riso International Symposium on Materials Science: Modelling of Structure and Mechanics of Materials from Microscale to Products, pp. 149-168.

Uenishi, A., Teodosiu, C., 2004. Constitutive modelling of the high strain rate behaviour of interstitial-free steel. Int. J. Plasticity 20 (4-5), 915-936.

Wang, J., Wagoner, R.H., 2005. A practical large-strain solid finite element for sheet forming. Int. J. Numer. Meth. Eng. 63 (4), 473-501.

Wang, C., Kinzel, G., Altan, T., 1993. Mathematical modeling of plane-strain bending of sheet and plate. J. Mater. Process. Technol. 39 (3-4), 279-304.

Yamada, Y., Yoshimur, N., Sakurai, T., 1968. Plastic stress-strain matrix and its application for the solution of elastic-plastic problems by the finite element method. Int. J. Mech. Sci. 10 (5), 348-354.

Yang, M., Akiyama, Y., Sasaki, T., 2004. Evaluation of change in material properties due to plastic deformation. J. Mater. Process. Technol. 151 (1-3), 232-236.

Yoshida, F., Uemori, T., 2003. A model of large-strain cyclic plasticity and its application to springback simulation. Int. J. Mech. Sci. 45 (10), 1687-1702.

Zhao, K.M., Lee, J.K., 2002. Finite element analysis of the three-point bending of sheet metals. J. Mater. Process. Technol. 122 (1), 6-11. 